Artigos originais

Economia e Sociedade, Campinas, Unicamp. IE.

http://dx.doi.org/10.1590/1982-3533.2021v30n3art04

\title{
Teoria do crescimento liderado pelas exportações: uma avaliação empírica para o Brasil *
}

\author{
Pedro Henrique Alves de Oliveira ** \\ Leandro dos Santos Maciel ${ }^{* * *}$
}

\begin{abstract}
Resumo
Dentre as diversas teorias do crescimento, a teoria export-led growth ressalta a importância das exportações sobre o nível de desenvolvimento e da produtividade em uma economia, em decorrência da geração de economias de escala e de uma maior eficiência. A análise da influência das exportações sobre o nível da produtividade no Brasil mostra-se de fundamental importância, uma vez que conclusões acerca desta relação podem provar-se úteis para a formulação de políticas públicas. Este trabalho analisou empiricamente o impacto das exportações sobre a produtividade na indústria de transformação no Brasil durante o período de 2002-2019. Com base em técnicas de séries temporais, os resultados mostraram que as exportações e a produtividade apresentam uma relação comum de longo prazo. Além disso, considerando as estimativas de um modelo de vetores autoregressivos com correção de erros, verificou-se evidências da influência das exportações sobre a produtividade, i.e., confirmando a teoria do crescimento liderado pelas exportações.
\end{abstract}

Palavras-chave: Exportações, Produtividade, Cointegração, Export led-growth, Modelos VECM.

\section{Abstract \\ Export-led growth theory: an empirical analysis of Brazil}

Among the various theories of growth, the export-led growth theory highlights the importance of exports on the level of development and productivity in an economy, due to the generation of economies of scale and greater efficiency. The analysis of the influence of exports on the level of productivity in Brazil is of fundamental importance, since conclusions about this relationship can prove to be useful for the formulation of public policies. This work empirically analyzed the impact of exports on productivity in the manufacturing industry in Brazil during the period 2002-2019. Based on time series techniques, the results showed that exports and productivity reflect the presence of long-run equilibrium. In addition, considering the estimates of an autoregressive vector model with error correction, there was evidence of the influence of exports on productivity, i.e., confirming the export-led growth theory.

Keywords: Exports, Productivity, Cointegration, Export-led growth, VECM models.

JEL: O47, L60, C32.

\section{Introdução}

Nos anos 90, o Brasil viu-se frente a um processo de abertura comercial, promovido por políticas que visavam abrir a economia do país ao ambiente competitivo criado pela globalização e maior integração dos mercados. Como exemplo de medidas que visavam este objetivo, podemos citar a eliminação das barreiras não tarifárias e a redução das tarifas médias do comércio externo - em 1987 estavam em torno de 130\%, e em 1994 foram reduzidas para 15\%. A intenção era desincentivar

\footnotetext{
${ }^{*}$ Artigo recebido em 21 de março de 2020 e aprovado em 22 de março de 2021.

${ }^{* *}$ Graduando do Departamento de Economia da Escola Paulista de Política, Economia e Negócios da Universidade Federal de São Paulo (EPPEN-UNIFESP), Osasco, SP, Brasil. E-mail: pedro.alves@ unifesp.br. ORCID: https://orcid.org/0000-0001-6092-2056.

${ }^{* * *}$ Professor Doutor do Departamento de Administração, Faculdade de Economia, Administração e Contabilidade da Universidade de São Paulo ((FEA-USP), São Paulo, SP, Brasil. E-mail: leandromaciel@ usp.br. ORCID: https://orcid.org/0000-0002-1900-7179.
} 
a proteção ao produto nacional, trazendo melhorias na atividade comercial, sobretudo na alocação de fatores produtivos e na criação de alicerces para a inserção de um Brasil mais eficiente na economia mundial. Internamente, também se verificaram processos que promoveram maior estabilidade ao cenário nacional, como o Plano Real e as privatizações.

No entanto, um dos maiores benefícios da abertura comercial não é apenas a intensificação da competitividade, mas também o aumento da produtividade, elemento esse essencial para o crescimento econômico. No âmbito teórico, existem diversas argumentações que buscam relacionar o crescimento das exportações com o aumento da produtividade. Em primeiro lugar, uma maior exposição à competição acaba por selecionar firmas mais eficientes (aquelas que possuem maior produtividade, por exemplo). No nível exportador, a competição internacional tende a ser maior do que a verificada em mercados domésticos, o que aumenta a tendência para a seleção de firmas que mostrem um maior nível de eficiência. Outras vertentes teóricas se apoiam em explicações voltadas à dinâmica industrial para o aumento da produtividade: argumenta-se que os exportadores devem lidar com os custos irrecuperáveis (sunk-costs) associados à entrada no mercado exportador, o que cria uma seleção de firmas ainda mais eficientes. Além disso, discussões teóricas também apontam que a maior produtividade das firmas exportadoras se relaciona ao conceito da exportação como um processo de aprendizado: o contato que os exportadores têm com o exterior permite um maior acesso a capitais e tecnologias inovadoras, permitindo-lhes um maior nível de eficiência e produtividade. Por fim, temos, ainda, a teoria do Export-Led Growth (ELG), que associa às exportações, enquanto componente autônomo da demanda agregada, um papel vital para a promoção da industrialização e do crescimento, como discutido por North (1955).

Apesar de amplamente discutida a relação entre exportação, produtividade e crescimento na teoria econômica, as pesquisas empíricas que buscam comprovar a teoria do ELG ainda estão se desenvolvendo e, no caso do Brasil, particularmente, ainda são escassas. Destacam-se trabalhos como os de Ferreira, Ellery e Gomes (2008), Hay (1997) e Rossi Jr. e Ferreira (1999), que encontram uma relação direta entre exportações e crescimento de produtividade, ainda que sob argumentações teóricas diferentes que explicam as interações associadas. Porém, conforme argumentam Bonelli e Pinheiro (2013), ainda não se definiu na literatura uma relação de causalidade explícita entre abertura comercial e produtividade. Os estudos que reconhecem a relação positiva entre a produtividade e abertura comercial, com foco em setores econômicos agregados, são mais frequentes, mas não desenvolvem um olhar específico sobre a relação entre a exportação e a produtividade na indústria de transformação, setor esse de grande importância para o crescimento de um país, sobretudo em economias emergentes, como a brasileira. A Organização Mundial do Comércio (OMC) aponta que o Brasil apresenta um nível de exportações acima da média mundial, com crescimento de 17,5\% no ano de $2017^{1}$. Além disso, a indústria de transformação, por sua vez, é responsável por cerca de 11,3\% do PIB do Brasil², segundo pesquisa da Confederação Nacional da Indústria (CNI) realizada em 2019.

Neste contexto, o presente trabalho avalia a relação entre exportações e produtividade na indústria de transformação brasileira no período de janeiro de 2002 até fevereiro de 2019. Dessa

(1) Fonte: http://www.mdic.gov.br/index.php/ultimas-noticias/3223-exportacoes-brasileiras-crescem-acima-da-media-mundial. Acesso em: 2 jul. 2019.

( 2 ) Fonte: https://noticias.portaldaindustria.com.br/noticias/economia/participacao-da-industria-na-economia-brasileira-sobepara-22-diz-cni/. Acesso em: 2 jul. 2019. 
forma, por meio de técnicas de séries temporais, é verificado se as variáveis que mensuram a produtividade e as exportações no Brasil, para a indústria de transformação, apresentam uma relação comum de longo prazo, ou seja, se são cointegradas, de forma a trazer evidências empíricas da teoria do ELG, isto é, do crescimento liderado pelas exportações. Em caso positivo de cointegração, um modelo de vetores autoregressivos com correção de erros é estimado para explicitar as dinâmicas de curto e longo prazos entre as variáveis, inclusive por meio da análise das respectivas funções de impulso-resposta e da decomposição da variância do erro de predição. Adicionalmente, as exportações serão mensuradas por meio do nível agregado (exportações totais, free on board - FOB) e especificamente para a indústria de transformação, com o objetivo de verificar os impactos da produtividade dessa indústria que afetam diretamente o setor, como para a capacidade exportadora global do país, de forma geral.

As contribuições dessa pesquisa consistem na seleção de um setor específico para se estudar a relação proposta pela teoria do crescimento liderado pelas exportações, amplamente avaliada na literatura e, sobretudo, por se tratar de um setor de grande relevância para a economia brasileira: a indústria de transformação. O trabalho ainda considera um período, 2002 a 2019, marcado por diferentes conjunturas econômicas e políticas associadas ao mercado externo. Além disso, para a análise de influências da atividade exportadora na produtividade de um país, o Brasil mostra-se como um caso particular de estudo, pois diversas estratégias de crescimento e industrialização foram implantadas ao longo de sua história. Entre os anos de 1950 e 1980, por exemplo, a estratégia dominante foi o modelo Import Substitution Industrialization (ISI), caracterizado por um maior fechamento da nação ao comércio internacional, priorizando-se os bens nacionais. Assim, a política econômica do ISI caracterizava-se por elevadas tarifas, presença de barreiras não tarifárias, proteção à indústria nascente, e superávits na balança comercial (Averburg, 1999). No começo dos anos 1990, as políticas econômicas retomam-se como prioridade à abertura comercial, tanto no sentido da importação quanto da exportação, inserindo a economia brasileira em linha com o novo contexto econômico promovido pela globalização.

Por fim, a análise acerca da relação entre exportações e produtividade na indústria de transformação mostra-se como um importante elemento para a condução de políticas públicas que tenham como objetivo promover o crescimento da produtividade e, consequentemente, garantir o crescimento em longo prazo do país, sobretudo em economias como a brasileira, em que a indústria de transformação é responsável por grande parte da matriz industrial.

O presente trabalho está organizado como segue. Uma revisão da literatura com estudos que tratam da relação entre exportação e produtividade (tanto no âmbito empírico quanto teórico) é apresentada na seção 1. A metodologia, que trata dos principais modelos de análise de séries temporais, compreende a seção 2. Os resultados e as respectivas discussões são apresentados na seção 3. A conclusão e indicações de pesquisa futura compreendem a última seção.

\section{Revisão bibliográfica}

\subsection{Literatura teórica}

As vantagens que o comércio internacional pode garantir a um país têm sido discutidas na literatura a partir das abordagens clássicas de Adam Smith e David Ricardo. Em sua obra "A Riqueza das Nações", Smith aponta que a expansão dos mercados externos (ou seja, o maior contato comercial 
entre as nações) poderia garantir uma maior especialização do trabalho, contribuindo para um aumento da produtividade. Sua conhecida "Teoria das Vantagens Absolutas" atesta que um país tem vantagem absoluta sobre outra economia quando necessita de uma quantidade menor de fatores de produção (trabalho, capital, tecnologia) para produzir um determinado bem (Smith, 1996).

Como consequência, David Ricardo estabelece a chamada "Teoria das Vantagens Comparativas", argumentando que, mesmo que um país não tenha nenhuma vantagem absoluta (ou seja, sendo incapaz de produzir qualquer mercadoria com custos mais baixos), ainda apresentará vantagem comparativa em relação a outras nações quando os bens são valorados em termos de seus custos de oportunidade. Portanto, será vantajoso para um certo país produzir mais de um determinado bem, garantindo uma vantagem comparativa em relação aos demais países, que apresentarão vantagem comparativa em outros bens (Ricardo, 1996). Assim sendo, os países deveriam produzir bens para os quais tenham vantagens comparativas (e não absolutas). Se todas as nações procedessem desta forma, o resultado seria benéfico no agregado, para o produto, o bem-estar e consequente aumento da produtividade.

Similarmente, Young (1928) associa o contato da indústria com o exterior como algo benéfico para as economias, de forma que toda firma pode realizar sua produção como um todo, ou se confinar a certos estágios do processo produtivo. Ainda assim, suas operações podem ficar sujeitas a mudanças (qualitativas ou quantitativas) quando amplia sua extensão de mercado, motivada, sobretudo, pela aparição de novos produtos, novas atividades, ou de indústrias emergentes. Segundo o autor, as economias de método de produção capitalista dependem de sua capacidade em alcançar mercados externos, o que lhes permite ganhos de escala. Buscando justificar o seu ponto de vista, Young (1928) aponta que a alta produtividade das indústrias estadunidenses é decorrente da ampla extensão do mercado doméstico, sem o uso de barreiras tarifárias. A presença de salários altos nos EUA seria uma consequência desta alta produtividade, e não uma causa (Young, 1928).

As teorias neoclássicas discutem o papel das exportações para o crescimento nas economias. Por exemplo, a "Teoria da Base Exportadora", desenvolvida por North (1955), explora o crescimento regional mediante o multiplicador de exportação, criado pela relação entre dois setores: o básico (bens e serviços, fora da área local) e o não-básico (voltado ao mercado doméstico). Embora seja desenvolvida como uma teoria unicausal (a exportação é o componente com maior influência no nível do produto), sendo aplicável apenas em pequenas regiões e, partindo da premissa de flexibilidade completa de preços, é destacada a importância das exportações para setores de maior especialização.

De forma alternativa, a "Moderna Teoria do Crescimento", proposta por Solow (1957), busca destacar que a função de produção liga o volume produzido por uma economia aos fatores de produção e ao estado de conhecimento tecnológico. Dentro de um contexto de maior abertura comercial, que promove aumentos no insumo capital e acesso a novas tecnologias, haverá melhorias nos níveis de produção e, consequentemente, de produtividade.

Contrariando o modelo de Solow, a "Teoria do Novo Crescimento", de Romer (1990), indica que a taxa de progresso tecnológico é exógena na função de produção, podendo ser estimulada por competição e por um maior nível de inovação. Melhorias na produtividade estariam, então, ligadas ao investimento em capital humano e ao avanço no conhecimento tecnológico. 
Bhagwati (1978) estabelece outras explicações para a relação entre exportação e crescimento. Dentre elas, destaca-se o fato de que exportações se concentram, em geral, em setores eficientes da economia (semelhante a ideia de vantagens comparativas de Ricardo). Quanto maior a eficiência das firmas, maior a especialização e, consequentemente, maior a produtividade. Além disso, uma maior exposição à competição internacional cria pressões para as indústrias que fazem parte do setor exportador a manter custos menores, assim como provém incentivos para mudanças tecnológicas que possam vir a impactar na produtividade.

Ainda nessa linha de pesquisa, a hipótese do "Export-Led Growth" (ELG), ou ainda conhecida como a teoria do crescimento liderado pelas exportações, foi introduzida por autores como Lamfalussy (1963), Beckerman (1965) e Kaldor (1970). O primeiro ressalta a relevância do modelo ELG por três razões: a exportação (enquanto gasto autônomo) é uma variável determinante da demanda agregada, sendo que a taxa de crescimento das exportações é fundamental para determinar a taxa de investimento de um país. Beckerman (1965), por sua vez, expressa uma visão semelhante em favor da teoria do ELG: uma expansão na atividade exportadora sinaliza um aumento na capacidade competitiva de um país.

Segundo Kaldor (1970), há quatro leis do crescimento. A primeira indica que uma maior taxa de crescimento da indústria manufatureira leva a um maior crescimento no produto nacional. A segunda afirma que o maior crescimento de tal indústria leva a um maior crescimento na produtividade do trabalho, devido aos retornos crescentes de escala. A terceira lei, por sua vez, explica que o crescimento não fica restrito pela oferta de trabalho dentro das indústrias manufatureiras, sendo determinado pela demanda no setor agrícola em um estágio mais primário de desenvolvimento e, depois, em estágios mais avançados, pela atividade exportadora. A quarta e última lei afirma que o crescimento a longo prazo é determinado pelo nível de exportação: quanto maior o crescimento da indústria manufatureira proporcionado pela atividade exportadora, maior será a transferência de trabalhadores em direção a setores econômicos mais produtivos, levando a uma taxa de produtividade cada vez mais elevada.

Thirwall (1979) estabelece uma lei que aproxima a taxa de crescimento de longo prazo de um país como a razão entre o crescimento das exportações e a elasticidade-renda da demanda por importações, pressupondo uma taxa de câmbio real relativamente constante. Davidson (1990) interpreta o contexto da chamada "Lei de Thirwall" para países em desenvolvimento, visto que esses produzem produtos primários e bens manufaturados de baixa qualidade, com uma baixa elasticidaderenda da demanda, de forma que tais países têm a tendência de crescer a uma taxa mais lenta do que países desenvolvidos.

Ainda assim, a hipótese ELG pode ser analisada fora do contexto criado pela Lei de Thirwall. Autores como Awokuse (2007) e Thornton (1996) discutem a causalidade entre exportações e crescimento econômico baseando-se nos argumentos das vantagens comparativas: a abertura comercial, promovida por uma maior atividade exportadora, permite que investimentos sejam concentrados em setores mais eficientes da economia. Neles, ocorre uma maior especialização, aumentando a produtividade. Além disso, o acesso a mercados externos e a pressão competitiva permitem a formação de economias de escala, sempre priorizando a redução de custos médios de longo prazo e o aumento da produção. 
Para Melo e Robinson (1992), a teoria do export-led growth tem como objetivo a industrialização e pode se dividir em duas formas de estratégia: a da "mão visível", que envolve uma estratégia intervencionista de "escolher os vencedores", ou seja, selecionar indústrias mais produtivas, promovendo sua atividade exportadora. A segunda forma está relacionada à da "mão invisível", operando nos mercados com pouca participação governamental, com incentivos horizontais, promovendo alocação eficiente de fatores. Para os autores, a adequação da teoria ELG justifica-se pela alta taxa de crescimento e pela ampla participação do comércio no PIB de um país. Além disso, aponta-se uma correlação positiva entre a atividade industrial e a taxa de produtividade total dos fatores de produção.

Semelhante ao argumento de Kaldor (1970), Melo e Robinson (1992) explicam que há um ajustamento contínuo dos fatores de produção, fornecido pelo setor agrícola em um estágio primário do desenvolvimento industrial. Os autores ainda observam que existe uma correlação positiva entre a expansão da atividade exportadora e o crescimento da produtividade total dos fatores de produção, sobretudo na indústria de transformação. Isto ocorre pelo uso de economias de escala, transferência de tecnologia e maiores incentivos promovidos pela competição.

Há também uma teoria alternativa a ELG, que inverte o nexo da causalidade: ou seja, o crescimento promoveria um aumento de produtividade, mediante um aumento de habilidades e tecnologia. Com isso, criar-se-á uma vantagem comparativa que facilitará as exportações. Tal teoria é a GLE (Growth-Led Export), abordada por Krugman (1984) e Lancaster (1980).

Melitz e Ottaviano (2008) partem de um modelo de firmas heterogêneas, atestando que uma maior abertura comercial leva a um processo de seleção de firmas mais produtivas, ocasionando um maior crescimento de produtividade, ainda que não de maneira direta: o market share será realocado em direção de firmas que possuem menores custos marginais.

Dessa forma, verificam-se diversos autores que apontam os benefícios das exportações sobre o nível de produtividade das firmas e, consequentemente, sobre o crescimento das economias, mesmo quando distintas vertentes teóricas são consideradas. A seguir são apresentados estudos que avaliam tais teorias empiricamente.

\subsection{Literatura empírica}

O trabalho de Feder (1982) testa a hipótese do ELG para os seguintes países: Argentina, Brasil, Chile, Taiwan, Colômbia, Costa Rica, Grécia, Hong Kong, Israel, Coreia, Malásia, México, Portugal, Singapura, África do Sul, Espanha, Turquia, Uruguai e Iugoslávia, durante os anos de 19641973. O autor verifica a evidência do modelo ELG, apontando que políticas que se voltam para a exportação e a abertura ao mercado externo conseguem levar as economias a uma melhor alocação de recursos. Ainda, segundo o autor, esse resultado ocorre devido ao fato de que setores exportadores e não exportadores apresentam, entre si, diferenças na produtividade marginal de fatores.

Knust e Marin (1989) buscam investigar a causalidade entre produtividade e exportação na Áustria e, por meio do teste de causalidade de Engle e Granger, os autores chegam a conclusão que existe uma relação unicausal positiva entre exportação e a produtividade. Além disso, destacam que tal relação não se verifica quando o câmbio está desvalorizado, o que geraria um impacto positivo 
sobre a atividade exportadora. Porém, destaca-se que a relação produtividade e exportação deve ser estendida a países em desenvolvimento antes de quaisquer conclusões em relação a execução de políticas públicas para promoção do setor exportador.

Shan e Tian (1998), com base na Teoria do Novo Crescimento de Romer (1990), considerando um modelo de Vetores Autoregressivos (VAR), testam a possibilidade de uma relação positiva entre exportação e crescimento no produto para a cidade de Shangai no período de 19901996. Os autores não conseguem verificar tal relação, argumentando que o desempenho excepcional do país no período analisado decorre de fatores domésticos, tais como investimentos externos e políticas públicas (reformas econômicas).

Awokuse (2003) testa a teoria ELG para o Canadá por meio da avaliação de cointegração e de testes de causalidade de Granger. Os resultados do trabalho apontam para a confirmação da influência das exportações no crescimento do produto e da produtividade, tanto no longo quanto no curto prazos. $\mathrm{O}$ autor associa esse resultado também como consequência da depreciação cambial do dólar canadense e da abertura comercial do país no mercado internacional.

Por meio de modelos VAR, testes de cointegração e de causalidade de Granger, Keong, Yusop e Liew (2005) testam a hipótese ELG para a Malásia. Em seus resultados, os autores concluem que a relação positiva entre produto e exportação, como prevista pela teoria ELG, é válida, no curto e longo prazos. Para um sucesso maior das implicações positivas da confirmação da ELG, aponta-se que deve haver políticas macroeconômicas para estabilizar a balança de pagamentos, a liberalização do comércio internacional, assim como medidas que busquem atrair investimento que se voltem para atividades exportadoras, em conjunto com taxas de câmbio estáveis.

Por meio de análises de cointegração e a partir de testes de causalidade de Granger, Herzer, Felicitas e Siliverstovis (2006) testa a hipótese ELG para o Chile entre 1960-2001. Segundo o autor, há uma relação comum de longo prazo entre as exportações provenientes da indústria de transformação e a produtividade no país. Além disso, argumenta-se que bens manufaturados apresentam um grande potencial para a tese export by learning ${ }^{3}$ para países importadores quando comparados com bens primários.

Kaushik e Arbenser (2008) analisam a possibilidade de uma relação de bicausalidade entre as exportações e o crescimento econômico para a Índia durante período de 1971-2005 por meio de testes de cointegração. Os resultados apresentados levam à conclusão de que há unicausalidade na relação, com as exportações influenciando o crescimento econômico no longo prazo, por meio de impactos na produtividade, por exemplo.

Ainda olhando para o caso da Índia, durante o período 1995-2008, Sharma e Mishra (2015) analisam a relação entre os níveis de importação, exportação e produtividade dentro da indústria de transformação, com base em duas medidas diferentes de produtividade: Fatores Totais da Produção (FTP) e Produtividade do Fator Trabalho (medida parcial de produtividade). Os resultados

(3) A teoria export by learning, ou processo de aprendizado a partir das exportações, relaciona o contato das economias com diferentes tecnologias e modos de produção para ganhos de produtividade. Tal hipótese foi discutida empiricamente por Liu (1993) para o Chile e por Clerides, Lach e Tybout (1998) para a Colômbia, Marrocos e México. Em ambos os casos, os autores encontram evidência positiva na influência do nível de exportação sobre a eficiência das firmas. 
apresentados indicaram que a produtividade, mensurada por ambas as medidas, aumenta (diminui) quando as firmas intensificam (reduzem) o comércio internacional. Isto ocorre graças ao efeito do learning-by-exporting, cujo impacto é maior na produtividade do trabalho do que na FTP. Segundo os autores, isto ocorre devido ao uso de técnicas intensivas em trabalho dentro da indústria de transformação indiana.

Silaghi (2009) testa a hipótese ELG e GLE (Growth-Led Export) para países da Europa Central e Oriental, sendo eles: Bulgária, República Tcheca, Estônia, Hungria, Letônia, Lituânia, Polônia, Romênia, Eslovênia e Eslováquia. Para isto, foi primeiro testada a existência da cointegração entre as séries de exportação e produtividade e, depois, usou-se testes de causalidade de Granger. A autora inseriu as importações como variável importante para a validação do modelo ELG, visto que uma expansão das exportações necessita de importações de bens (como os de capital e tecnologias). A hipótese ELG foi comprovada para a Bulgária, República Tcheca e Estônia. Quando as importações foram incluídas, o modelo ELG tornou-se válido apenas para a República Tcheca e Lituânia. O modelo GLE, por sua vez, foi comprovado empiricamente apenas para a Hungria, Romênia e Eslovênia.

Para o Brasil, boa parte dos estudos focam na relação entre exportação e crescimento em termos do nível agregado. Fasano Filho (1988) mostra uma correlação positiva entre o nível de exportação e de crescimento econômico do Brasil no período de 1969-1984. Com base em uma função de produção neoclássica, o autor verifica que tal correlação é elevada, especialmente quando as taxas de exportações provenientes da indústria manufatureira são consideradas. Ainda ressalta que, embora o Brasil tenha sido uma economia fechada no período analisado, o desempenho das exportações mostrou-se como uma variável importante para o crescimento econômico brasileiro.

Ghatak, Milner e Utkulu (1997) apontam que as avaliações da produtividade em setores agregados podem gerar conclusões equivocadas: mesmo se existem evidências a favor da hipótese ELG em certos setores de exportação, isto talvez não vá se refletir em um nível agregado, pois podem existir indústrias que não tenham (ou mesmo precisem) de qualquer relação com o comércio internacional.

O trabalho de Hay (1997) analisa os efeitos da liberalização comercial no Brasil na década de 90 sobre a produtividade total dos fatores, sobre o market share e sobre o lucro em uma amostra de 349 firmas, usando dados longitudinais (em painel) para seu estudo. $\mathrm{O}$ autor conclui que as firmas analisadas responderam à liberalização do comércio: a produtividade total cresceu de maneira considerável, sobretudo devido ao catch-up tecnológico (ou seja, a atualização das empresas em termos tecnológicos ao entrarem em contato com novas técnicas de produção), e melhoras provenientes da $x$-efficiency (o comportamento de uma empresa devido à falta de pressão competitiva).

Nessa mesma linha de pesquisa, Silva (2004) busca investigar se a liberalização comercial teve uma influência positiva na produtividade durante o período de 1989-1999 em 47 setores da indústria de transformação. De acordo com a produção total dos fatores, verificou-se um crescimento da produtividade a partir dos anos 90, especialmente para os setores mais ligados à tecnologia. Argumenta-se que isto se deu graças à abertura comercial, que criou um ambiente de maior competição e aquisição de insumos importados. 
A validade da teoria export-led growth e growth-led export é testada para o Brasil entre o primeiro trimestre de 1975 até o segundo semestre de 2008 por Campos (2009). Por meio do teste de cointegração de Engle-Granger e da estimação de um modelo VAR, o autor atesta uma relação bicausal entre o PIB e o comércio externo do país, argumentando que o crescimento das exportações poderia levar a maiores ganhos de produtividade, decorrente da redução dos custos de produção e, ao mesmo tempo, o aumento do produto poderia contribuir para o aumento da produtividade, favorecendo a expansão da atividade exportadora.

Hidalgo e Mata (2009) testam as diferenças entre as produtividades das firmas exportadoras e não exportadoras no Brasil, mediante o teste não-paramétrico para distribuições de probabilidades de Kolmogrov-Smirnov. Comprovadas as diferenças entre as produtividades, os autores analisaram se tais diferenças são justificadas por processos de seleção e/ou processos de aprendizado no comércio internacional. Os autores chegaram à conclusão de que a auto-seleção predomina sobre os processos de aprendizagem.

Por fim, Araujo e Soares (2011) usam testes de causalidade de Granger para verificar se há uma relação bicausal ou unicausal entre exportação e crescimento econômico (seja pelas teorias GLE ou ELG) entre 1991 e 2010 no Brasil. Os autores concluem que a relação de bicausalidade é válida, ou seja, as exportações influenciam o nível do produto e vice-versa.

Silva, Bezerra e Lima (2012) fazem uma análise da possibilidade de influência das exportações sobre a produtividade dentro da indústria da transformação brasileira durante o período de 1992-2010, considerando vetores autoregressivos com correção de erros e testes de causalidade. Os resultados obtidos pelo trabalho indicam que as exportações influenciam a produtividade positivamente, exceto quando há a presença de desvalorização cambial. Por isso, a teoria ELG é considerada parcialmente verdadeira.

De forma geral, pode-se perceber que ainda não há um consenso na literatura acerca da relação entre exportações e produtividade, sobretudo para o Brasil, o que demanda mais pesquisas nessa área de estudo uma vez que os resultados podem trazer indício de adoção de políticas públicas para garantir um maior crescimento econômico.

\section{Metodologia}

A metodologia desse trabalho consiste em uma abordagem de econometria de séries temporais para avaliar a relação entre exportações e produtividade para a indústria de transformação no Brasil. Com isso, será considerada a aplicação de testes de raiz unitária para verificar a estacionariedade das séries, assim como de testes de cointegração, com o objetivo de testar a existência de possíveis relações comuns de longo prazo entre exportações e produtividade. Os testes de cointegração também serão conduzidos com a inclusão do câmbio real, de forma a determinar se tal variável é exógena ou endógena no sistema associado, uma vez que desempenha papel fundamental no nível das relações do comércio exterior. Com base nos resultados de cointegração, serão estimados os modelos apropriados para capturar as relações, ou seja, técnicas de vetores autoregressivos (VAR) ou de vetores autoregressivos com correção de erros (VECM). Adicionalmente à análise dos modelos estimados, serão construídas as respectivas funções impulso- 
resposta e a decomposição da variância do erro para configurar as principais relações entre exportações e produtividade.

\subsection{Testes de raiz unitária}

Para avaliar a estacionariedade das séries, o teste de raiz unitária de Dickey e Fuller (1981) é considerado. O objetivo do teste, de forma geral, consiste em verificar se determinada série temporal $\left\{y_{t}\right\}, t=1, \ldots, T$, é não estacionária, ou seja, se seus momentos, como média e variância, são variantes no tempo. Os autores partem do seguinte modelo para representar o processo gerador da série temporal em questão:

$y_{t}=\rho y_{t-1}+e_{t}$

em que $\rho$ corresponde ao coeficiente autoregressivo e $e_{t}$ um distúrbio aleatório de tipo ruído branco.

Dessa forma, a hipótese nula do teste é dada por $H_{0}: \rho=1$, que indica a presença de raiz unitária. Uma vez que o modelo em (1) se caracteriza como com variância "explosiva" quando a hipótese nula não é rejeitada, verificamos a presença de raiz unitária. Alternativamente, subtraindo em ambos os lados da Eq. (1) o termo $y_{t-1}$, obtemos:

$\Delta y_{t}=\gamma y_{t-1}+\varepsilon_{t}$.

onde $\Delta y_{t}=y_{t}-y_{t-1}$.

Dessa forma, em (2), temos que $\gamma=\rho-1$ e, assim, a hipótese nula de raiz unitária passa a ser do tipo $H_{0}: \gamma=0$, que implica em $\rho=1$, i.e., presença de raiz unitária, forma essa usual em testes de hipóteses. A não rejeição da hipótese nula implica que a série é não estacionária. Se a série em primeira diferença, $\Delta y_{t}$, indicar estacionariedade, dizemos que $y_{t}$ é integrada de ordem unitária, $I(1)$. Caso $y_{t}$ é estacionária em nível, a série é integrada de ordem zero, $I(0)$.

A dinâmica em (2) pode incluir termos determinísticos, como uma constante e/ou tendência. Nesses casos, são obtidos os respectivos modelos alternativos para o processo gerador da série em que se avalia a hipótese de raiz unitária:

$\Delta y_{t}=\mu+\gamma y_{t-1}+\varepsilon_{t}$,

$\Delta y_{t}=\mu+\delta t+\gamma y_{t-1}+\varepsilon_{t}$,

em que $\mu$ é uma constante, $t$ o indexador temporal, para capturar a tendência, e $\delta$ seu coeficiente associado.

Por sua vez, o teste de Dickey-Fuller Aumentado (ADF) busca superar problemas de autocorrelação e heterocedasticidade nas formulações das Eqs. (2)-(4). Logo, por meio da inclusão de termos defasados da série temporal associada, em primeira diferença, mantém-se a hipótese nula da presença de raiz unitária para os três modelos associados ao processo gerador da série, ou seja, sem constante, com constante, e com constante e tendência, respectivamente:

$\Delta y_{t}=\gamma y_{t-1}+\sum_{i=1}^{p} \theta_{i} \Delta y_{t-i}+\varepsilon_{t}$

$\Delta y_{t}=\mu+\gamma y_{t-1}+\sum_{i=1}^{p} \theta_{i} \Delta y_{t-i}+\varepsilon_{t}$, 
$\Delta y_{t}=\mu+\delta t+\gamma y_{t-1}+\sum_{i=1}^{p} \theta_{i} \Delta y_{t-i}+\varepsilon_{t}$,

onde $\theta_{i}$ são os coeficientes associados aos termos autoregressivos de $\Delta y_{t-i}$, com $i=1, \ldots, p$.

O número de defasagens dos modelos, $p$, pode ser determinado com base em critérios de informação, tais como o de Akaike (AIC) e Bayesiano (BIC), ou seja, levando-se em consideração o ajuste e o número de parâmetros estimados, no sentido de penalizar modelos menos parcimoniosos. Os valores críticos do teste são os tabulados por Dickey e Fuller (1981) e dependem do tamanho da amostra, $T$, e do tipo de processo gerador da série considerado - Eqs. (5)-(7).

De forma alternativa, o teste KPSS, de Kwiatkowisk, Phillips, Schmidt e Shin (1992), também considerado nesse trabalho, como complementar ao teste ADF, adota a hipótese nula de estacionariedade (integração de ordem zero ou ausência de raiz unitária), enquanto que a hipótese alternativa é a de não estacionariedade. O teste KPSS supõe o seguinte processo gerador de série em análise:

$y_{t}=\delta t+x_{t}+\varepsilon_{t}$,

onde $x_{t}=x_{t-1}+v_{t}, v_{t} \sim$ i.i.d. $\left(0, \sigma_{v}^{2}\right)$. Logo, testa-se a hipótese nula de estacionariedade com $H_{0}: \sigma_{v}^{2}=0$, contra $H_{1}: \sigma_{v}^{2}>0$. Se $H_{v}$ não for rejeitada, o processo é estacionário, i.e. integrado, de ordem nula, $I(0)$.

\subsection{Teste de cointegração de Johansen}

Se as séries temporais em análise são estacionárias em nível, $I(0)$, adotamos um modelo de vetores autoregressivos (VAR) para mensurar as relações associadas. Por outro lado, caso os testes de raiz unitária indiquem que as séries são não estacionárias e integradas de mesma ordem, torna-se necessário avaliar se há uma relação comum de longo prazo entre elas, i.e., se são cointegradas. Para verificar se as séries em questão são cointegradas, será considerado o teste de cointegração de Johansen (1988). A cointegração pode ser definida como uma tendência aleatória comum que as variáveis dentro de um modelo podem assumir no longo prazo mesmo com a presença de desvios de curto prazo.

Para entender o teste de cointegração de Johansen, deve-se partir de um modelo de vetores autoregressivos (VAR) da seguinte forma:

$\boldsymbol{y}_{t}=A_{0}+A_{1} \boldsymbol{y}_{t-1}+\cdots+A_{p} \boldsymbol{y}_{t-p}+\boldsymbol{\varepsilon}_{t}$,

onde $\boldsymbol{y}_{t}=\left[y_{1, t}, y_{2, t}, \ldots, y_{n, t}\right]^{\prime}$ é um vetor de ordem $n$ das variáveis que compõem o sistema, $A_{0} \mathrm{o}$ vetor $n \times 1$ dos termos de intercepto, $A_{j}$ refere-se a matriz de coeficientes de ordem $n \times n, j=$ $1, \ldots, p,\left\{\varepsilon_{t}\right\}$ é um processo $n$ dimensional de termos de erro i.i.d. com média zero e matriz de covariâncias $\Sigma_{\varepsilon}$.

Os modelos VAR requerem a condição de estacionariedade das séries. Quando não se verifica tal restrição, sobretudo em séries econômicas, há a necessidade de se avaliar a possibilidade de que a combinação linear das variáveis possa ser estacionária, isto é, se são cointegradas. Na presença de cointegração é possível modelar dinâmicas de curto e longo prazos entre as variáveis. Os componentes do vetor $\boldsymbol{y}_{t}$ são ditos cointegrados de ordem $(d, b)$, denotado por $C I(d, b)$ se: i) todos os componentes de $\boldsymbol{y}_{\boldsymbol{t}}$ são integrados de ordem $d$; ii) e existe um vetor de cointegração $\boldsymbol{\beta}=$ 
$\left[\beta_{1}, \beta_{2}, \ldots, \beta_{n}\right]^{\prime}$ tal que $\boldsymbol{\beta} \boldsymbol{y}_{t}=\beta_{1} y_{1, t}+\beta_{2} y_{2, t}+\cdots+\beta_{n} y_{n, t}$ é integrado de ordem $(d-b)$, com $b>0$ (Enders, 2015). Considerando as variáveis econômicas em equilíbrio de longo prazo quando $\beta_{1} y_{1, t}+\beta_{2} y_{2, t}+\cdots+\beta_{n} y_{n, t}=0$, o desvio a esse equilíbrio, $\boldsymbol{e}_{t}$, conhecido também como termo de correção de erros, é $\boldsymbol{\beta} \boldsymbol{y}_{t}=\boldsymbol{e}_{t}$, um processo estacionário. Portanto, tal relação deve ser incorporada na análise da dinâmica do sistema, constituindo um modelo com correção de erros.

Assim como nas equações do modelo de Dickey-Fuller, podemos escrever a Eq. (9) em termos de um modelo autoregressivo com correção de erros (VECM) da seguinte maneira:

$\Delta y_{t}=\pi y_{t-1}+\sum_{i=1}^{p-1} \pi_{i} \Delta y_{t-i}+\varepsilon_{t}$,

onde $\pi=-\left(I-\sum_{i=1}^{p} A_{i}\right)$ e $\pi_{i}=-\sum_{j=i+1}^{p} A_{j}$.

A principal vantagem de se escrever um modelo de correção de erros se deve ao fato de que se incorpora informações de longo e curto prazo mediante ajustes nas variações de $\boldsymbol{y}_{t}$. Na equação em (10), uma questão fundamental consiste na determinação do posto da matriz $\pi$, que é igual ao número de vetores de cointegração independentes, i.e., o número de relações de cointegração do sistema. Se o posto de $\pi$ é nulo, temos um modelo VAR em primeira diferença. Por exemplo, se o posto de $\pi$ é igual a 1 , há um único vetor de cointegração e o componente $\pi \boldsymbol{y}_{t-1}$ corresponde ao termo de correção de erros. Johansen (1988) ainda propõe a decomposição de $\pi$ em duas matrizes da seguinte forma:

$\pi=\boldsymbol{\alpha} \boldsymbol{\beta}^{\prime}$,

sendo que $\boldsymbol{\alpha}$ é uma matriz de ordem $n \times r$, onde $n$ é o número de variáveis do sistema e $r$ o número de relações de cointegração (posto de $\pi$ ), com os parâmetros que representam a velocidade de ajustamento no curto prazo à dinâmica comum de longo prazo; e $\boldsymbol{\beta}$, também de ordem $n \times r$, é uma matriz de coeficientes de cointegração.

Dessa forma, a análise da presença de cointegração se resume à verificação do posto da matriz $\pi$. Johansen (1988) propôs duas estatísticas para testar a significância das raízes caraterísticas de $\pi$, o que resulta na determinação do número de vetores (relações) de cointegração. O teste do traço, cuja hipótese nula é a da existência de $\bar{r}$ vetores de cointegração, contra a hipótese alternativa de $r>\bar{r}$. Rejeitar a hipótese nula significa inferir que há mais de $\bar{r}$ vetores de cointegração. De forma alternativa, o teste de máximo autovalor, que é mais robusto que o anterior, tem a hipótese nula assumindo que há $\bar{r}$ vetores de cointegração, enquanto a hipótese alternativa estabelece que há $\bar{r}+1$ vetores. As estatísticas associadas ao teste do traço e do máximo autovalor são obtidas por, respectivamente:

$\lambda_{\text {trace }}(r)=-T \sum_{i=r+1}^{n} \ln \left(1-\hat{\lambda}_{i}\right)$,

$\lambda_{\max }(r, r+1)=-T \ln \left(1-\hat{\lambda}_{r+1}\right)$,

onde $\hat{\lambda}_{i}$ são os valores estimados das raízes características (autovalores) da matriz $\pi$ e $T$ é o número de observações da amostra considerada. 


\subsection{Modelos VAR e VECM}

Em caso de ausência de relações de cointegração entre as séries avaliadas, um modelo VAR deverá ser considerado. Os modelos de vetores autoregressivos são uma extensão do modelo autoregressivo e de médias móveis (ARMA) para análises com várias variáveis (equações simultâneas), e tem como origem a necessidade de tratar as variáveis de um sistema de maneira simétrica, sem criar hipóteses acerca de possíveis correlação entre tais variáveis. A abordagem realizada pelo VAR permite verificar as relações entre as variáveis que compõem o sistema mediante instrumentos como suas funções impulso-resposta e com base na análise da decomposição da variância.

Por exemplo, um modelo VAR de ordem 1, VAR(1), para o caso bivariado pode ser expresso como:

$y_{1, t}=a_{1,0}+a_{1,1} y_{1, t-1}+a_{1,2} y_{2, t-1}+\varepsilon_{1, t}$,

$y_{2, t}=a_{2,0}+a_{2,1} y_{1, t-1}+a_{2,2} y_{2, t-1}+\varepsilon_{2, t}$,

onde $a_{i, j}$ são os coeficientes associados, $i, j=0,1, \ldots, 2, \varepsilon_{1, t}$ e $\varepsilon_{2, t}$ são distúrbios do tipo ruído-branco não correlacionados.

Note que a forma generalizada do VAR, em termos matriciais, é representada como na equação em (9). A determinação da ordem do modelo VAR, $p$ - número de defasagens, dá-se com base na análise de critérios de informação para obtenção da estrutura mais parcimoniosa. Os parâmetros são estimados por mínimos quadrados, sob a condição de estacionariedade das séries em questão. O VAR permite que cada variável tenha sua dinâmica baseada em suas próprias defasagens e em defasagens das demais variáveis. De fato, verifica-se que a vantagem do modelo VAR está no fato de que sua estrutura não requer conhecimento sobre forças exógenas que atuam sobre os processos que compõem a estrutura multivariada.

Em caso da evidência de relações de cointegração entre as variáveis analisadas, um modelo de vetores autoregressivos com correção de erros (VECM) deve ser estimado para incorporar a dinâmica comum de longo prazo. Novamente, por exemplo, um modelo VECM de ordem unitária, $\operatorname{VECM}(1)$, bivariado, e com uma relação de cointegração, posto $(\pi)=1$, pode ser representado como (Enders, 2015):

$\Delta y_{1, t}=a_{1,0}+\alpha_{1}\left(y_{1, t}-\beta y_{2, t}\right)+a_{1,1} \Delta y_{1, t-1}+a_{1,2} \Delta y_{2, t-1}+\varepsilon_{1, t}$,

$\Delta y_{2, t}=a_{2,0}+\alpha_{2}\left(y_{1, t}-\beta y_{2, t}\right)+a_{2,1} \Delta y_{1, t-1}+a_{2,2} \Delta y_{2, t-1}+\varepsilon_{2, t}$,

onde $\boldsymbol{\alpha}=\left[\alpha_{1}, \alpha_{2}\right]^{\prime}$ são os parâmetros de velocidade de ajustamento dos desvios da relação comum de longo prazo. Quanto maior $\alpha_{1}$, maior a resposta de $y_{1, t}$ aos desvios passados da relação de longo prazo. Se ambos os parâmetros $\alpha_{1}$ e $\alpha_{2}$ são estatisticamente iguais a zero, não há relação comum no longo prazo, sem a necessidade do termo de correção de erros. $\boldsymbol{\beta}^{\prime}=[1,-\beta]$ é o vetor dos parâmetos de cointegração normalizado, ou seja, $y_{1, t}-\beta y_{2, t}=0$. As Eqs. (16)-(17) são representadas, em termos matriciais, em (10). De forma geral, o modelo VECM corresponde a um modelo VAR em primeira diferença com a inclusão dos termos de correção de erros $\alpha_{1}\left(y_{1, t}-\beta y_{2, t}\right) \mathrm{e}$ $\alpha_{2}\left(y_{1, t}-\beta y_{2, t}\right)$. 
A determinação do número de defasagens do modelo se dá a partir dos critérios de seleção, objetivando o modelo mais parcimonioso. Nesse trabalho, independente da estrutura adotada, incluise nos modelos variáveis dummies para mensurar a possibilidade da presença de sazonalidade, assim como considerou a inclusão do câmbio real como variável adicional ao sistema (que será definida como endógena ou exógena com base nos testes de cointegração). A significância do coeficiente associado ao câmbio permitirá a análise da relevância de tal variável macroeconômica na relação entre exportações e produtividade.

Por fim, com base nos modelos estimados, as análises incluem também a estimação das respectivas funções impulso-resposta e da decomposição da variância do erro de previsão. A função impulso-resposta é uma forma útil para se explorar as interações entre as variáveis que compõem o modelo, que se traduz em mostrar os efeitos de choques nos componentes de erro aleatórios sobre a dinâmica das variáveis do modelo em questão (Enders, 2015). Alternativamente, a decomposição de variância dos erros de previsão permite analisar as inter-relações entre as variáveis do sistema, ou seja, a contribuição percentual de cada variável para a variação das variáveis dependentes.

\section{Análise empírica}

\subsection{Base de dados}

Os dados considerados nessa pesquisa são de periodicidade mensal, tendo início em janeiro de 2002 e término em fevereiro de 2019, compreendendo as seguintes variáveis: 1) o volume financeiro das exportações no agregado (FOB), expresso em milhões de USD e obtido no MDIC (Ministério de Indústria e Comércio); 2) o volume financeiro das exportações da indústria de transformação, construída pela soma dos volumes financeiros (expressos em milhões de USD) de cada setor dessa indústria, obtidos no MDIC; 3) o índice de horas trabalhadas na indústria de transformação, dado obtido pela Confederação de Nacional da Indústria (CNI); 4) o índice de produção da indústria de transformação, divulgado pela Pesquisa Industrial Mensal (PIM-PF). A medida de produtividade da indústria de transformação foi calculada como a razão entre o índice de produção (PIM) e o índice de horas trabalhadas. Coletou-se também a série do índice de preços ao atacado (IPA) dos Estados Unidos, obtida do Bureau of Labor Statistics (BLS). Com base no IPA, as medidas das exportações foram deflacionadas em valores correntes de fevereiro de 2019. Por fim, cabe destacar que o período selecionado para as variáveis é decorrente da disponibilidade dos dados da série do PIM-PF quando da realização da pesquisa. Foi coletada também a série mensal do IPCA (Índice de Preços ao Consumidor Amplo) e da taxa de câmbio nominal (R\$/US\$), de forma a se calcular a taxa de câmbio real.

A identificação de dos setores da indústria de transformação foi realizada de acordo com o Quadro 1, classificação essa desenvolvida pelo Departamento de Pesquisas e Estudos Econômicos da FIESP. O Quadro 2 apresenta um resumo das séries estudadas nesta pesquisa. 
Quadro 1

Setores que compõem a indústria de transformação no Brasil segundo a FIESP

\begin{tabular}{|l|}
\hline \multicolumn{1}{|c|}{ Setores da Indústria de Transformação } \\
\hline Produtos Alimentícios \\
Confecção de Artigos de Vestuário e Acessórios \\
Produtos de Metal, exc. Máquinas e Equipamentos \\
Veículos Automotores, Carrocerias e Autopeças \\
Produtos de Minerais Não-Metálicos \\
Produtos de Borracha e de Material Plástico \\
Máquinas e Equipamentos \\
Artefatos de Couro, Artigos para Viagem e Calçados \\
Produtos Têxteis \\
Móveis \\
Produtos Químicos \\
Metalurgia \\
Máquinas, Aparelhos e Materiais Elétricos \\
Produtos de Madeira \\
Manutenção, Reparação e Instalação de Máquinas e Ópticos \\
Coque, Derivados do Petróleo e Biocombustíveis \\
Produtos Diversos \\
Bebidas \\
Impressão e Reprodução de Gravações \\
Outros Equipamentos de Transporte, exc. Veículos Automotores \\
Produtos Farmoquímicos e Farmacêuticos \\
Produtos do Fumo
\end{tabular}

Fonte: Departamento de Pesquisas e Estudos Econômicos da FIESP.

Quadro 2

Descrição das variáveis consideradas para mensurar a relação entre exportação e produtividade na indústria de transformação no Brasil

\begin{tabular}{|ccc|}
\hline Símbolo & Significado & Unidade de medida \\
\hline $\operatorname{Exp}_{t}^{F O B}$ & Exportação no agregado & US\$ (em milhões) \\
$\Delta E x p_{t}^{F O B}$ & Exportação no agregado em primeira diferença & US\$ (em milhões) \\
$\operatorname{Exp}_{t}^{I T}$ & Exportação na indústria de transformação & US\$ (em milhões) \\
$\Delta E x p_{t}^{I T}$ & Exportação na indústria de transformação em primeira & US\$ (em milhões) \\
$\operatorname{Prod}_{t}$ & diferença & US\$ (em milhões) \\
$\Delta \operatorname{Prod}_{t}$ & Produtividade do fator trabalho & Índice \\
$e_{t}$ & Produtividade do fator trabalho em primeira diferença & R\$US\$ \\
$\Delta e_{t}$ & Câmbio real & R\$US\$ \\
\hline
\end{tabular}

A Figura 1 apresenta as séries das exportações (agregada - FOB - e da indústria de transformação) e da produtividade da indústria de transformação. 
Figura 1

Evolução mensal da exportação (em nível agregado e da indústria de transformação) e da medida de produtividade da indústria de transformação no período de janeiro de 2002 a fevereiro de 2019

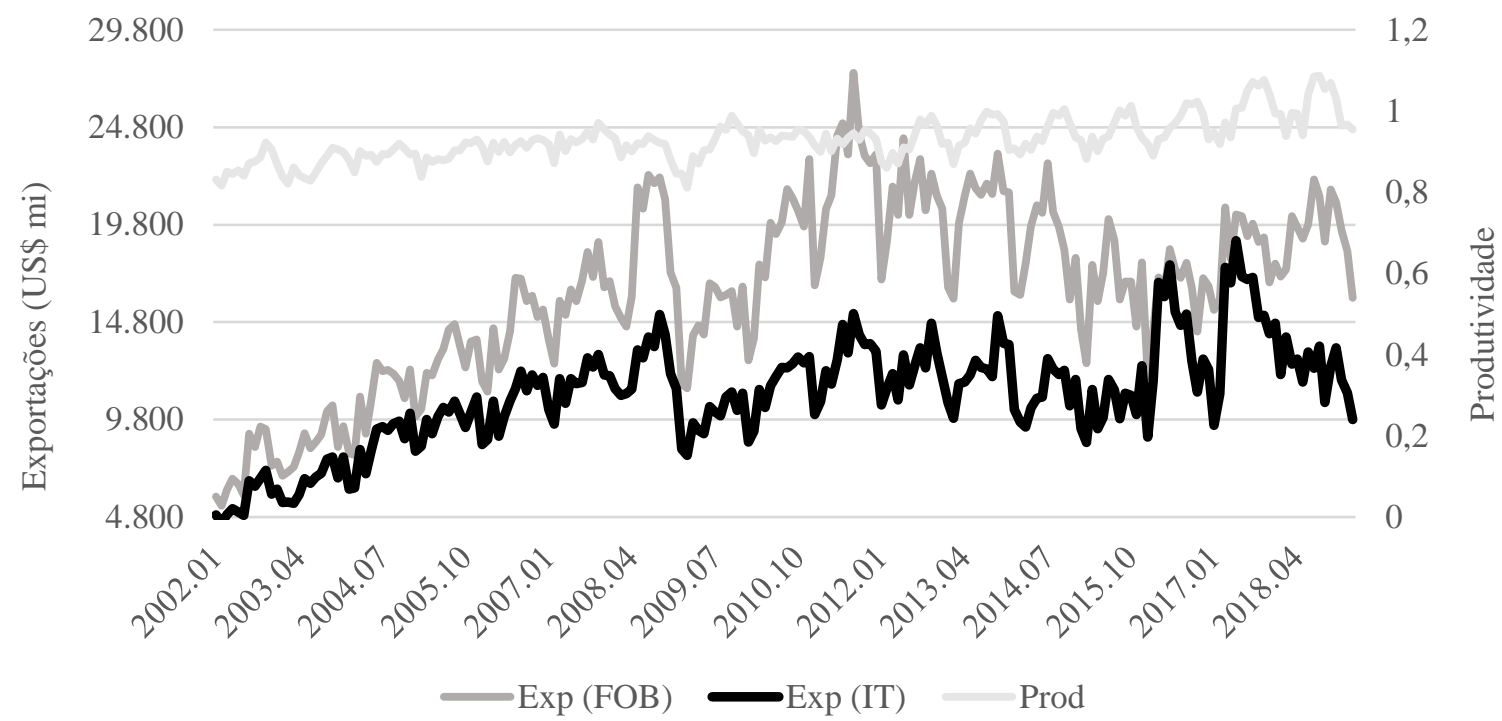

A análise das séries em períodos particulares revela a importância do ciclo de commodities (negociadas sobretudo com a China, um dos maiores parceiros comerciais do Brasil). Os níveis de exportação se encontram em franca ascensão até meados de 2008/início de 2009, devido aos efeitos da crise de 2008.

Ambas as séries de exportação apresentam uma tendência de crescimento ao longo do período analisado, o que pode ser uma indicação de não estacionariedade. No entanto, é necessário realizar os procedimentos econométricos formais para a realização de qualquer inferência. Além disso, há indícios de sazonalidade nas séries avaliadas, requerendo a possível inclusão de dummies sazonais para controlar essa dinâmica particular.

A análise econométrica conduzida consiste em inicialmente avaliar se as séries são não estacionárias (possuem presença de raiz unitária), mediante os testes ADF e KPSS. Caso as séries sejam não estacionárias e de mesma ordem de integração, procede-se para o teste de cointegração de Johansen, para verificar se há uma relação comum de longo prazo entre as medidas de exportação e a produtividade. Adicionalmente, é verificado se o câmbio real pode ser considerado uma variável exógena nesse sistema. Por fim, se as séries apresentarem uma relação de longo prazo, i.e., forem cointegradas, será estimado um modelo de correção de erros, VECM. Caso contrário, estima-se um modelo VAR. Em seguida, serão interpretados os resultados da decomposição da variância do erro de previsão e da função impulso-resposta dos modelos estimados. Todas as análises foram realizadas no software R na versão 3.6.0. Além disso, inclui-se no modelo dummies sazonais, para cada mês do ano, para controlar possíveis efeitos de sazonalidade nas séries.

\subsection{Testes de raiz unitária e cointegração}

A Tabela 1 apresenta os resultados do teste ADF de raiz unitária para as séries analisadas. $\mathrm{O}$ número de defasagens foi selecionado de acordo com o critério de informação Bayesiano (BIC), e $\tau$ 
indica o valor crítico do teste, conforme calculado por Dickey e Fuller (1981), para diferentes níveis de significância.

Com base nos resultados do teste Dickey-Fuller Aumentado (Tabela 1), observa-se que as séries referentes a exportação no agregado (FOB) e a produtividade são não estacionárias em nível (independente da forma funcional do processo gerador da série considerado no modelo, i.e., sem constante e tendência, com constante e com constante e tendência). Porém, passam a ser estacionárias em primeira diferença, indicando integração de ordem unitária. As defasagens foram selecionadas de acordo com o critério de informação Bayesiano (BIC). A série das exportações da indústria de transformação é não estacionária para o modelo sem constante e estacionária para o modelo com constante e com tendência determinística. Quando o teste é realizado para a primeira diferença, observa-se que o modelo sem constante passa a indicar que a série é estacionária. Nesse caso, mostrase necessária a condução de testes adicionais de raiz unitária.

Procedendo para o teste KPSS, os resultados são apresentados na Tabela 2. O teste KPSS revela que todas as séries analisadas em nível são não estacionárias a um nível de significância de $1 \%$. Quando em primeira diferença, os resultados do teste indicam que todas as séries passam a ser estacionárias 6 .

Tabela 1

Resultados do teste de raiz unitária ADF para as séries de exportações, produtividade e câmbio real no período de janeiro de 2002 a fevereiro de 2019

\begin{tabular}{|c|c|c|c|c|c|c|}
\hline Variável & Modelo & Estatística & $\tau_{1 \%}$ & $\tau_{5 \%}$ & $\tau_{10 \%}$ & Defasagens \\
\hline \multirow{3}{*}{$\operatorname{Exp}_{t}^{F O B}$} & - & 0,7453 & $-2,58$ & $-1,95$ & $-1,62$ & 8 \\
\hline & $\mathrm{c}$ & $-2,1957$ & $-3,46$ & $-2,88$ & $-2,57$ & 8 \\
\hline & $\mathrm{c}, \mathrm{t}$ & $-1,6832$ & $-3,99$ & $-3,43$ & $-3,13$ & 8 \\
\hline \multirow{3}{*}{$\Delta E x p_{t}^{F O B}$} & - & $-9,4409 * * *$ & $-2,58$ & $-1,95$ & $-1,62$ & 7 \\
\hline & $\mathrm{c}$ & $-9,5472 * * *$ & $-3,46$ & $-2,88$ & $-2,57$ & 7 \\
\hline & $\mathrm{c}, \mathrm{t}$ & $-8,6908 * * *$ & $-3,99$ & $-3,43$ & $-3,13$ & 7 \\
\hline \multirow{3}{*}{$\operatorname{Exp}_{t}^{I T}$} & - & $-0,4806$ & $-2,58$ & $-1,95$ & $-1,62$ & 1 \\
\hline & $\mathrm{c}$ & $-3,5873$ & $-3,46$ & $-2,88$ & $-2,57$ & 1 \\
\hline & $\mathrm{c}, \mathrm{t}$ & $-4,2195$ & $-3,99$ & $-3,43$ & $-3,13$ & 1 \\
\hline \multirow{3}{*}{$\Delta E x p_{t}^{I T}$} & - & $-8,1655 * * *$ & $-2,58$ & $-1,95$ & $-1,62$ & 10 \\
\hline & $\mathrm{c}$ & $-8,2688 * * *$ & $-3,46$ & $-2,88$ & $-2,57$ & 10 \\
\hline & $\mathrm{c}, \mathrm{t}$ & $-8,5443 * * *$ & $-3,99$ & $-3,43$ & $-3,13$ & 10 \\
\hline \multirow{3}{*}{$\operatorname{Prod}_{t}$} & - & 1,605 & $-2,58$ & $-1,95$ & $-1,62$ & 9 \\
\hline & $\mathrm{c}$ & $-0,5587$ & $-3,46$ & $-2,88$ & $-2,57$ & 9 \\
\hline & $\mathrm{c}, \mathrm{t}$ & $-2,3035$ & $-3,99$ & $-3,43$ & $-3,13$ & 9 \\
\hline \multirow{3}{*}{$\Delta \operatorname{Prod}_{t}$} & - & $-9,8307 * * *$ & $-2,58$ & $-1,95$ & $-1,62$ & 10 \\
\hline & $\mathrm{c}$ & $-10,2423 * * *$ & $-3,46$ & $-2,88$ & $-2,57$ & 10 \\
\hline & $\mathrm{c}, \mathrm{t}$ & $-10,2282 * * *$ & $-3,99$ & $-3,43$ & $-3,13$ & 10 \\
\hline \multirow{3}{*}{$e_{t}$} & - & $-2,0934 * *$ & $-2,58$ & $-1,95$ & $-1,62$ & 1 \\
\hline & $\mathrm{c}$ & $-4,026 * * *$ & $-3,46$ & $-2,88$ & $-2,57$ & 1 \\
\hline & $\mathrm{c}, \mathrm{t}$ & $-3,2201 *$ & $-3,99$ & $-3,43$ & $-3,13$ & 1 \\
\hline \multirow{3}{*}{$\Delta e_{t}$} & - & $-10,1867 * * *$ & $-2,58$ & $-1,95$ & $-1,62$ & 1 \\
\hline & $\mathrm{c}$ & $-10,2513 * * *$ & $-3,46$ & $-2,88$ & $-2,57$ & 1 \\
\hline & $\mathrm{c}, \mathrm{t}$ & $-10,614 * * *$ & $-3,99$ & $-3,43$ & $-3,13$ & 1 \\
\hline
\end{tabular}

Nota: $(*),(* *),(* * *)$ representam significância a $10 \%, 5 \%$ e $1 \%$, respectivamente; $(-),(\mathrm{c}),(\mathrm{c}, \mathrm{t})$ indicam modelo sem constante e sem tendência, com constante, e com constante e tendência, respectivamente.

(6) Testes adicionais de raiz unitária (Phillips-Perron e ERS) também foram conduzidos, e ambos apontaram para não estacionariedade quando as séries estão em nível. Quando em primeira diferença, passam a ser estacionárias. Os resultados podem ser requisitados aos autores. 
Pedro Henrique Alves de Oliveira, Leandro dos Santos Maciel

Tabela 2

Resultados do teste de raiz unitária KPSS para as séries de exportações, produtividade e câmbio real no período de janeiro de 2002 a fevereiro de 2019

\begin{tabular}{ccccc}
\hline Variável & Estatística & $\tau_{1 \%}$ & $\tau_{5 \%}$ & $\tau_{10 \%}$ \\
\hline $\operatorname{Exp}_{t}^{F O B}$ & $2,4845^{* * *}$ & 0,739 & 0,463 & 0,347 \\
$\Delta \operatorname{Exp}_{t}^{F O B}$ & 0,0864 & 0,739 & 0,463 & 0,347 \\
$\operatorname{Exp}_{t}^{I T}$ & $2,3478^{* * *}$ & 0,739 & 0,463 & 0,347 \\
$\Delta \operatorname{Exp}_{t}^{I T}$ & 0,0749 & 0,739 & 0,463 & 0,347 \\
$\operatorname{Prod}_{t}$ & $2,6742^{* * *}$ & 0,739 & 0,463 & 0,347 \\
$\operatorname{Prod}_{t}$ & 0,0198 & 0,739 & 0,463 & 0,347 \\
$e_{t}$ & $1,7562^{* * *}$ & 0,739 & 0,463 & 0,347 \\
$\Delta e_{t}$ & 0,1368 & 0,739 & 0,463 & 0,347 \\
\hline
\end{tabular}

Nota: $(*),(* *),(* * *)$ representam significância a $10 \%, 5 \%$ e $1 \%$, respectivamente.

Atestada a presença de raiz unitária comum, I(1), dentre as séries, procedeu-se para a avaliação de cointegração. Para o teste de cointegração de Johansen, foram analisados dois modelos distintos: o primeiro, relaciona a medida de exportação no agregado (FOB) com a produtividade; e um segundo, que relaciona a exportação na indústria de transformação com a produtividade. $\mathrm{O}$ objetivo em se estimar os dois modelos é mensurar o impacto da produtividade da indústria de transformação nas exportações do próprio setor, assim como em nível agregado. Adicionalmente, em cada um dos modelos, a variável câmbio foi incluída, tanto de forma exógena quanto endógena. Uma variável pode ser considerada endógena no sistema quando, ao ser adicionada no modelo, adiciona também uma relação de cointegração na relação. Quando é exógena, esta relação adicional de cointegração não existe.

A Tabela 3 mostra os resultados do teste de cointegração de Johansen com a variável câmbio considerada endógena, enquanto que a Tabela 4 traz a mesma análise, mas com o câmbio real como variável exógena. Cabe notar que os modelos dos testes de cointegração foram testados considerando a forma com constante e sem constante para o vetor de cointegração. Ainda, considerou-se os resultados da estatística do máximo autovalor - Eq. (13) - por constituir de uma hipótese alternativa mais restritiva que a estatística do traço - Eq. (12).

Quando se comparam os resultados das Tabelas 3 e 4, observa-se que, em ambos os casos, há apenas 1 relação de cointegração, tanto para o câmbio endógeno, como exógeno. Ou seja, a inclusão do câmbio como variável endógena não produziu relações de cointegração adicionais. Logo, o câmbio real deve ser considerado uma variável exógena no sistema.

Além disso, observa-se que em ambos os modelos (tanto o que considera a exportação no agregado - FOB, quanto a exportação do setor de transformação - IT), atesta-se uma relação de cointegração entre as variáveis, ainda que em níveis de significância diferentes. Logo, é possível afirmar que deve ser usado uma especificação de vetor de correção de erros (VECM) para os dois sistemas analisados. 
Teoria do crescimento liderado pelas exportações: uma avaliação empírica para o Brasil

Tabela 3

Resultados do teste de cointegração de Johansen para os modelos que consideram o câmbio real como variável endógena no sistema com base nos modelos sem e com constante

\begin{tabular}{cccccccc}
\hline Modelo & $H_{0}$ & Defasagens & Modelo & Estatística & $\tau_{1 \%}$ & $\tau_{5 \%}$ & $\tau_{10 \%}$ \\
\hline & $r=2$ & 1 & - & 2,98 & 11,65 & 8,18 & 6,5 \\
& $r=1$ & 1 & - & 5,59 & 19,19 & 14,90 & 12,91 \\
$\left(\Delta \operatorname{Exp}_{t}^{F O B}, \Delta \operatorname{Prod}_{t}, \Delta e_{t}\right)$ & $r=0$ & 1 & - & $20,26^{*}$ & 25,75 & 21,07 & 18,9 \\
\cline { 2 - 8 } & $r=2$ & 1 & $\mathrm{c}$ & 3,35 & 12,97 & 9,24 & 7,52 \\
& $r=1$ & 1 & $\mathrm{c}$ & 6,12 & 20,20 & 15,67 & 13,75 \\
& $r=0$ & 1 & $\mathrm{c}$ & $20,46^{*}$ & 26,81 & 22,00 & 19,77 \\
\hline & $r=2$ & 1 & - & 3,25 & 11,65 & 8,18 & 6,5 \\
$\left(\Delta \operatorname{Exp}_{t}^{I T}, \Delta \operatorname{Prod}_{t}, \Delta e_{t}\right)$ & $r=1$ & 1 & - & 5,26 & 19,19 & 14,90 & 12,91 \\
& $r=0$ & 1 & - & $25,93 * * *$ & 25,75 & 21,07 & 18,9 \\
\cline { 2 - 8 } & $r=2$ & 1 & $\mathrm{c}$ & 3,52 & 12,97 & 9,24 & 7,52 \\
& $r=1$ & 1 & $\mathrm{c}$ & 5,79 & 20,20 & 15,67 & 13,75 \\
& $r=0$ & 1 & $\mathrm{c}$ & $25,97 * * *$ & 26,81 & 22,00 & 19,77 \\
\hline
\end{tabular}

Nota: $(*),(* *),(* * *)$ representam significância a $10 \%, 5 \%$ e $1 \%$, respectivamente; $(-)$ e (c) indicam modelo sem constante e sem tendência, e com constante, respectivamente.

Tabela 4

Resultados do teste de cointegração de Johansen para os modelos que consideram o câmbio real como variável exógena no sistema com base nos modelos sem e com constante

\begin{tabular}{cccccccc}
\hline Modelo & $H_{0}$ & Defasagens & Modelo & Estatística & $\tau_{1 \%}$ & $\tau_{5 \%}$ & $\tau_{10 \%}$ \\
\hline & $r=1$ & 2 & - & 5,39 & 11,65 & 8,18 & 6,5 \\
$\left(\Delta \operatorname{Exp}_{t}^{F O B}, \Delta \operatorname{Prod}_{t}\right)$ & $r=0$ & 2 & - & $20,11 * * *$ & 19,19 & 14,90 & 12,91 \\
\cline { 2 - 8 } & $r=1$ & 2 & $\mathrm{c}$ & 5,39 & 12,97 & 9,24 & 7,52 \\
& $r=0$ & 2 & $\mathrm{c}$ & $20,14 * *$ & 20,2 & 15,67 & 13,75 \\
\hline & $r=1$ & 1 & - & 5,03 & 11,65 & 8,18 & 6,5 \\
$\left(\Delta \operatorname{Exp}_{t}^{I T}, \Delta \operatorname{Prod}_{t}\right)$ & $r=0$ & 1 & - & $23,99 * * *$ & 19,19 & 14,90 & 12,91 \\
\cline { 2 - 8 } & $r=1$ & 1 & $\mathrm{c}$ & 5,08 & 12,97 & 9,24 & 7,52 \\
& $r=0$ & 1 & $\mathrm{c}$ & $24,07 * * *$ & 20,2 & 15,67 & 13,75 \\
\hline
\end{tabular}

Nota: $(*),(* *),(* * *)$ representam significância a $10 \%, 5 \%$ e $1 \%$, respectivamente; (-) e (c) indicam modelo sem constante e sem tendência, e com constante, respectivamente.

\subsection{Resultados modelos VECM}

O modelo VECM estimado para a relação $\left(\triangle E x p_{t}^{F O B}, \triangle \operatorname{Prod}_{t}\right)$ é representado como segue:

$$
\begin{aligned}
& \Delta E x p_{t}^{F O B}=-\underset{(613,1692)}{1.209,8384^{*}}-\underset{(0,0436)}{0,1816^{* * *}}\left(\operatorname{Exp}_{t-1}^{F O B}+36.648,66 \operatorname{Prod}_{t-1}\right)-\underset{(0,0708)}{0,2503^{* * *}} \Delta \operatorname{Exp}_{t-1}^{F O B}
\end{aligned}
$$

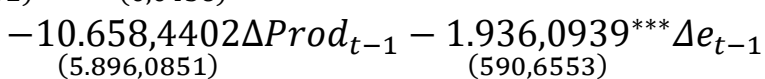

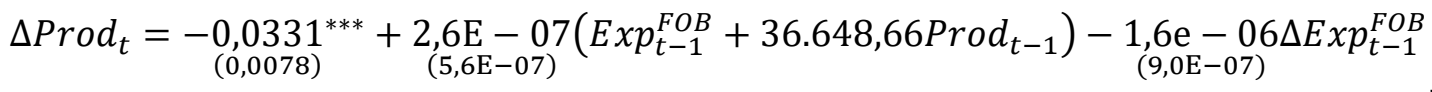

$$
\begin{aligned}
& \underset{(0,0753)}{-0,1298^{*}} \Delta \operatorname{Prod}_{t-1}-\underset{(0,0075)}{0,0036 \Delta e_{t-1}}
\end{aligned}
$$


onde os valores em parêntesis são os respectivos erros-padrão das estimativas, e (***), (**) $\left(^{*}\right)$ indicam significância estatística a 1\%, 5\% e 10\%, respectivamente. Foram inseridas dummies sazonais no sistema para controlar a sazonalidade das séries. As estimativas das variáveis dummies mensais foram significativas indicando, portanto, a necessidade do controle da sazonalidade para não viesar os resultados. Suas estimativas foram omitidas para simplificar a interpretação dos resultados.

O modelo é estacionário porque ambas as equações (especificamente no vetor de correção de erros) fornecem uma combinação linear estacionária, capturando a relação de cointegração entre as duas variáveis. Cabe ressaltar também que, dentre os coeficientes $\alpha$ 's estimados, $-0,1816$ na Eq. (18) e 2,6E-07 na Eq. (19), que acompanham os respectivos termos de correção de erros, apenas $\alpha_{1}=$ $-0,1816$ é significativo, indicando que a produtividade não responde significativamente aos desvios da relação comum de longo prazo ( $\alpha_{2}=2,6 \mathrm{E}-07$ é não significativo).

A análise dos coeficientes $\alpha^{\prime}$ s, pertencentes ao vetor de correção de erros deve ser feita de duas maneiras: comparação de seus valores em módulo e a análise da significância de ambos. A comparação em módulo mostra que o coeficiente da primeira equação é maior do que o coeficiente da segunda equação $(|-0,1816|>|2,6 \mathrm{E}-07|)$. Devido a isto, é possível afirmar que a variável que responde mais a desequilíbrios no curto prazo é a variável referente a $\Delta E x p_{t}^{F O B}$ (exportação no agregado). Já a $\Delta \operatorname{Prod}_{t}$ não responde aos desvios de equilíbrio dos períodos anteriores, indicando que, para o primeiro modelo, é a produtividade que afeta o nível de exportação. Ou seja, confirma-se a relação GLE (Growth-Led Export), sugerida por autores como Krugman (1984) e Lancaster (1980), na qual o crescimento econômico levaria ao aumento da produtividade, criando, assim, uma vantagem comparativa que facilita as exportações. Isto se verifica justamente pelo fato do coeficiente $\alpha$ associado ser não significativo na Eq. (19). Além disso, a análise do coeficiente associado ao câmbio real, nas duas equações, revela que tal variável é significativa em sua influência sobre as exportações - Eq. (18) (o que era de se esperar, afinal o valor do câmbio expressa a relação entre duas moedas e será essencial para a determinação do nível de exportação entre as nações). Já no caso da produtividade, o câmbio não tem impacto significativo sobre o nível de produtividade - Eq. (19), sendo mais afetada pela oferta real dos fatores de produção e pelo nível de tecnologia.

Adicionalmente, estimou-se o modelo VECM para o modelo $\left(\Delta E x p_{t}^{I T}, \Delta \operatorname{Prod}_{t}\right)$, considerando as exportações da indústria da transformação, e não em nível agregado. Obteve-se o seguinte modelo estimado:

$$
\begin{aligned}
& \Delta \operatorname{Exp}_{t}^{I T}=\underset{(999,2909)}{-3347,9295^{* * *}}-\underset{(0,0512)}{0,1763^{* * *}}\left(\operatorname{Exp}_{t-1}^{I T}+35.175,09 \operatorname{Prod}_{t-1}\right)-\underset{(0,0743)}{0,1622^{* *}} \Delta E x p_{t-1}^{I T} \\
& \underset{(4.517,6132)}{-10.699,3557^{* *}} \Delta \operatorname{Prod}_{t-1}-\underset{(351,7976)}{599,6756^{*}} \Delta e_{t-1} \\
& \Delta \operatorname{Prod}_{t}=\underset{(0,0162)}{0,0029}+\underset{(8,3 \mathrm{E}-07)}{2,1 \mathrm{E}-06^{* *}}\left(\operatorname{Exp}_{t-1}^{I T}+35.175,09 \operatorname{Prod}_{t-1}\right)-\underset{(1,2 \mathrm{E}-06)}{2,9 \mathrm{E}-06^{* *}} \Delta E x p_{t-1}^{I T} . \\
& \underset{(0,0753)}{-0,1079^{*}} \Delta \operatorname{Prod}_{t-1}+\underset{(0,0057)}{0,0098^{*}} \Delta e_{t-1}
\end{aligned}
$$

As estimativas das variáveis dummies mensais para controlar a sazonalidade das séries também apresentaram significância estatística, mas foram aqui omitidas para simplificar as análises. Da mesma forma que o modelo anterior, deve-se buscar a análise dos coeficientes de velocidade de ajustamento, -0,1763 na Eq. (20) e 2,1E-06 na Eq. (21). Primeiramente, estes coeficientes vão 
mensurar a velocidade de ajuste no curto prazo para retomar a tendências comum de longo prazo. Ambas as estimativas são significantes (embora a níveis de significância diferentes), o que significa que as variáveis são afetadas pelo restabelecimento da relação de longo prazo, ou seja, respondem significativamente aos desvios passados da relação comum. Comparando seus valores em módulo, observa-se que é $\alpha_{1}$ (associado a $\Delta E x p_{t}^{I T}$ ) que apresenta uma maior dominância na relação $(|-0,1763|>|2,1 \mathrm{E}-06|)$, portanto, os efeitos dos desvios da dinâmica de longo prazo impactam mais as exportações do que a produtividade. De forma geral, especificamente para a indústria de transformação, tanto a produtividade afeta as exportações (conforme a teoria GLE), quanto as exportações afetam a produtividade (de acordo com a teoria ELG, Export-Led Growth, na qual o aumento do comércio internacional promove ganhos de escala, permitindo um aumento na produtividade).

O câmbio real foi significativo a $10 \%$ tanto para a dinâmica das exportações quanto para a produtividade. Cabe notar, também, que essa variável assume uma relação negativa com as variáveis $\operatorname{Exp}_{t}^{F O B}$ - modelo das Eqs. (18)-(19) - e $E x p_{t}^{I T}$ - modelo das Eqs. (20)-(21). Isto ocorre pois quando a taxa de câmbio real está valorizada, o produto nacional está mais caro quando comparado ao produto estrangeiro. Logo, o nível de exportação será afetado negativamente (os produtos vendidos ao exterior ficarão relativamente mais caros). De maneira inversa, quando a taxa de câmbio real está desvalorizada, o produto nacional ficará mais barato em relação ao produto estrangeiro, estimulando positivamente a atividade exportadora.

Avaliadas as estimativas de ambos os modelos, parte-se para a análise das funções impulsoresposta e da decomposição da variância do erro de previsão. No modelo que conta com exportação no agregado $(\mathrm{FOB})$ e produtividade, representado por $\left(\Delta \operatorname{Exp}_{t}^{F O B}, \Delta \operatorname{Prod}_{t}\right)$, as funções impulsoresposta são apresentadas nas Figuras 2 e 3.

Figura 2

Função impulso-resposta de um choque em na variável exportação (FOB) e com resposta para ela mesma

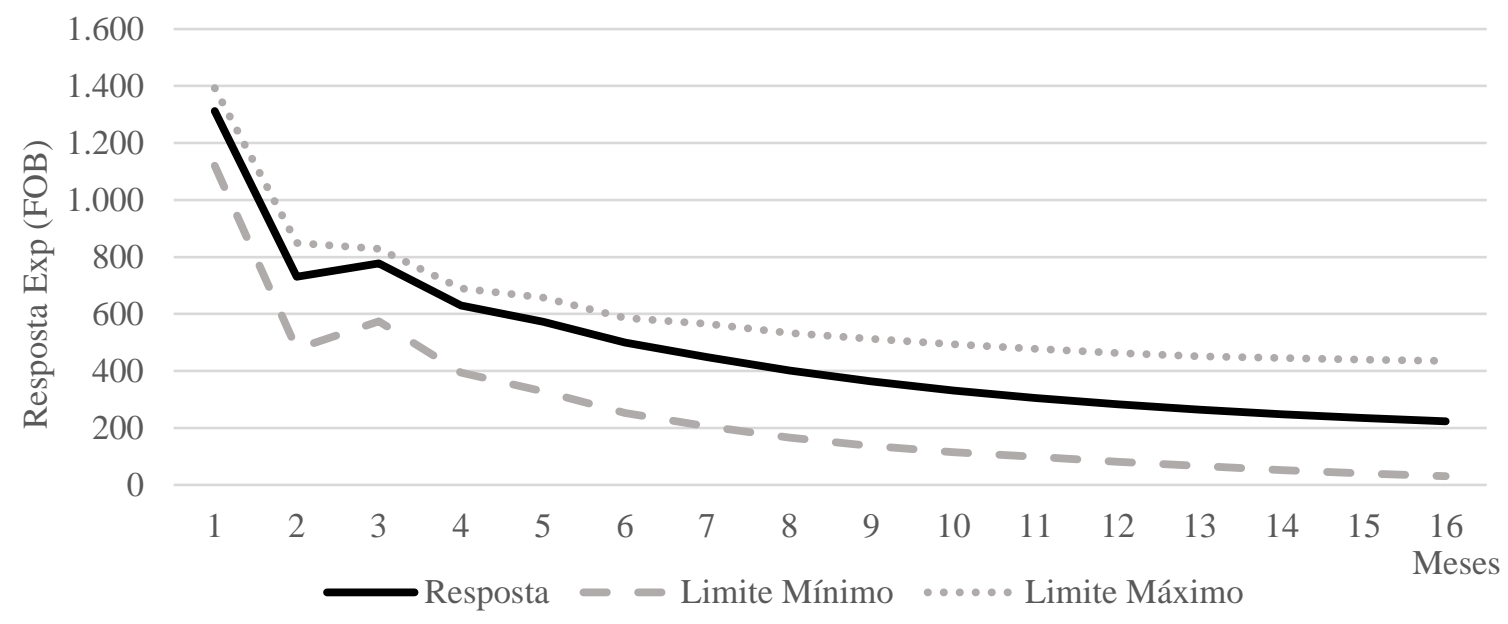


Figura 3

Função impulso-resposta de um choque em na variável exportação (FOB) e com resposta para na produtividade

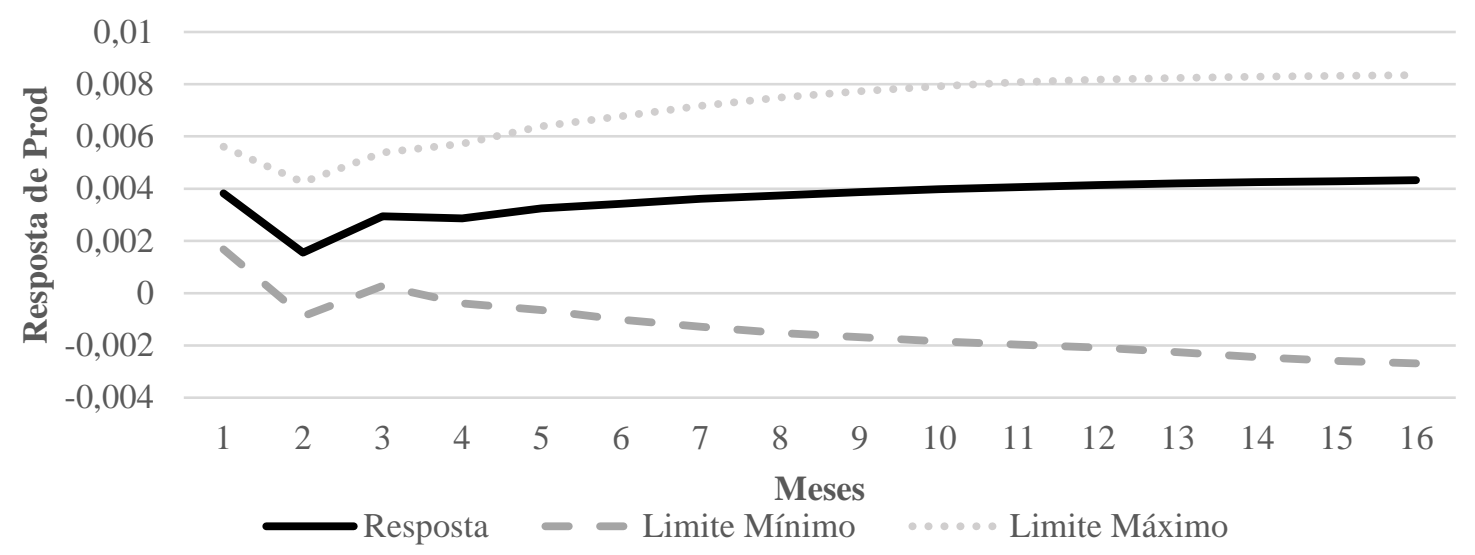

A Figura 2 mostra que um choque nas exportações (FOB) gera um efeito positivo sobre as próprias exportações. $\mathrm{O}$ efeito, embora positivo, tendem a decrescer até o segundo mês, e tem uma leve subida até o terceiro mês. A partir de então, o efeito tende a assumir uma taxa decrescente (ainda que positiva). A Figura 3, por sua vez, mostra que o choque das exportações produz um efeito positivo sobre a produtividade do trabalho. $\mathrm{O}$ efeito é decrescente até o $2^{\circ}$ mês. E então tende a se manter positivo e crescente (embora encontre uma leve estagnação do $3^{\circ}$ até o $4^{\circ}$ mês). Esta função impulsoresposta mostra que a resposta da produtividade frente ao choque nas exportações tende a não apresentar respostas crescentes imediatas (afinal, a produtividade só assume um ritmo de crescimento constante a partir do $4^{\circ}$ mês).

Para o modelo que considera as exportações da indústria de transformação, $\left(\Delta \operatorname{Exp}_{t}^{I T}, \Delta \operatorname{Prod}_{t}\right)$, por sua vez, apresenta as funções impulso-resposta representadas nas Figuras $4 \mathrm{e}$ 5. A Figura 4 mostra que um choque nas exportações da indústria de transformação produzirá uma resposta positiva sobre as próprias exportações, porém decrescente conforme o tempo passa. A Figura 5 revela que um choque das exportações no setor produz um choque positivo, porém cuja taxa de variação varia conforme o tempo passa. Inicialmente, o efeito é decrescente (até o $2^{\circ}$ mês). A partir daí, passa a ser crescente de maneira permanente. Ou seja, inicialmente um choque nas exportações produz um efeito inicial decrescente sobre a produtividade. Somente a partir do segundo mês é que o choque cria uma resposta positiva e crescente sobre a produtividade do trabalho. 
Figura 4

Função impulso-resposta de um choque em na variável exportação (IT) e com resposta para ela mesma

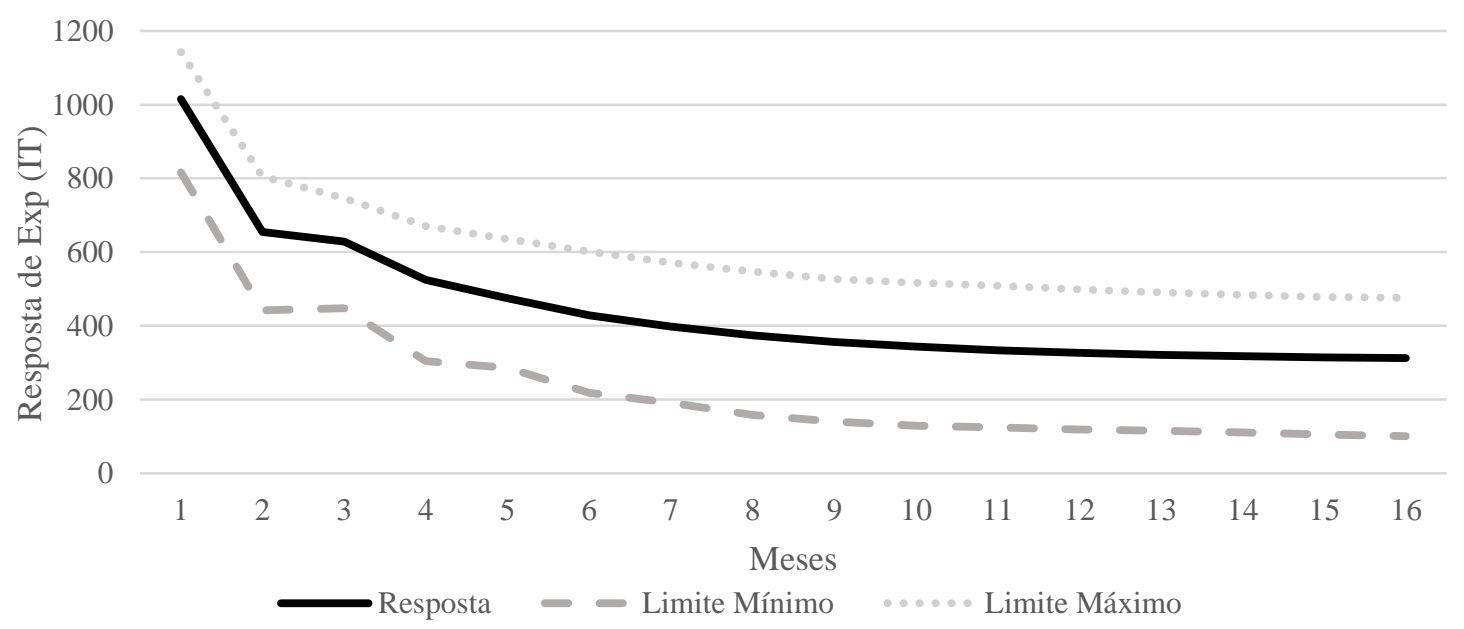

Em ambas as funções impulso-resposta que relacionam exportação (seja no agregado ou no setor) com a produtividade, há uma semelhança nos resultados: um efeito positivo, porém inicialmente decrescentes.

Figura 5

Função impulso-resposta de um choque em na variável exportação (IT) e com resposta para na produtividade

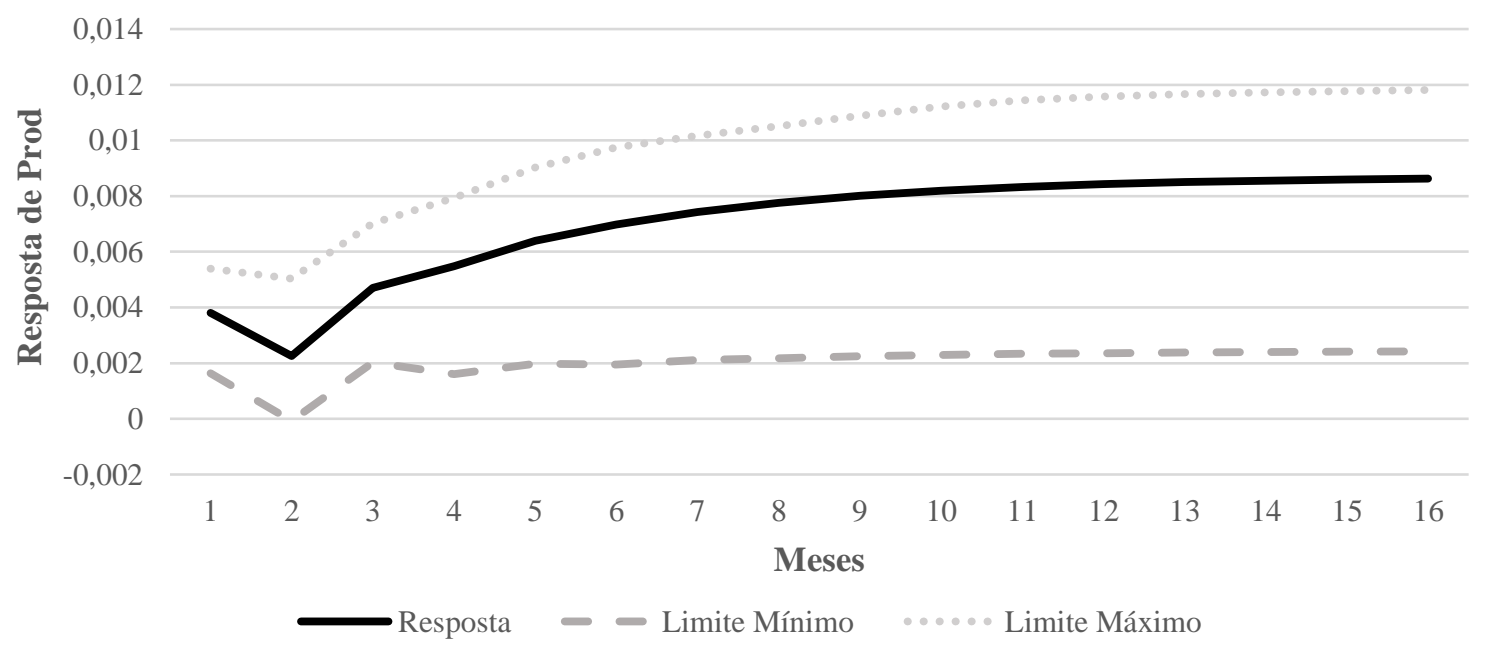

Na Tabela 5, é apresentada a decomposição da variância do erro de previsão do modelo que usa as exportações em nível agregado, isto é, $\left(\Delta E x p_{t}^{F O B}, \Delta \operatorname{Prod}_{t}\right)$. 
Tabela 5

Decomposição da variância do erro de previsão do modelo entre exportação (FOB) e produtividade

\begin{tabular}{ccccc}
\hline \multicolumn{2}{c}{$\Delta \operatorname{Exp}_{t}^{F O B}$} & \multicolumn{2}{c}{$\Delta \operatorname{Prod}_{t}$} \\
\hline Período & $\Delta E x p_{t}^{F O B}(\%)$ & $\Delta \operatorname{Prod}_{t}(\%)$ & $\Delta \operatorname{Exp}_{t}^{F O B}(\%)$ & \multicolumn{1}{c}{$\operatorname{Prod}_{t}(\%)$} \\
\hline 1 & 100,0000 & 0,0000 & 5,2052 & 94,7948 \\
3 & 99,6249 & 0,3751 & 3,7113 & 96,2887 \\
5 & 98,3464 & 1,6536 & 4,0659 & 95,9341 \\
7 & 95,6083 & 4,3918 & 4,6512 & 95,3488 \\
9 & 91,8428 & 8,1572 & 5,2443 & 94,7557 \\
11 & 87,5239 & 12,4761 & 5,7913 & 94,2087 \\
13 & 83,0330 & 16,9670 & 6,2786 & 93,7215 \\
15 & 78,6267 & 21,3733 & 6,7058 & 93,2942 \\
17 & 74,4531 & 25,5469 & 7,0781 & 92,9219 \\
19 & 70,5829 & 29,4172 & 7,4018 & 92,5982 \\
21 & 67,0379 & 32,9621 & 7,6836 & 92,3164 \\
23 & 63,8123 & 36,1877 & 7,9295 & 92,0705 \\
25 & 60,8859 & 39,1141 & 8,1449 & 91,8551 \\
27 & 58,2323 & 41,7677 & 8,3344 & 91,6656 \\
29 & 55,8241 & 44,1760 & 8,5019 & 91,4981 \\
\hline
\end{tabular}

Observa-se que a produtividade chega a explicar $44 \%$ da variância do erro de previsão da exportação do agregado (FOB) para uma previsão de 29 meses à frente. No entanto, a exportação em FOB tem menor capacidade em explicar os erros de previsão de produtividade, chegando em uma previsão de 29 meses à frente a explicar somente 8,5\%.

A Tabela 6 apresenta a decomposição da variância do erro de predição do modelo que considera as exportações da indústria de transformação, $\left(\Delta \operatorname{Exp} p_{t}^{I T}, \Delta \operatorname{Prod}_{t}\right)$.

Tabela 6

Decomposição da variância do erro de previsão do modelo entre exportação (IT) e produtividade

\begin{tabular}{ccccc}
\hline \multicolumn{3}{c}{$\Delta \operatorname{Exp}_{t}^{I T}$} & \multicolumn{2}{c}{$\Delta \operatorname{Prod}_{t}$} \\
\hline Período & $\Delta \operatorname{Exp}_{t}^{I T}(\%)$ & $\Delta \operatorname{Prod}_{t}(\%)$ & $\Delta \operatorname{Exp}_{t}^{I T}(\%)$ & $\Delta \operatorname{Prod}_{t}(\%)$ \\
\hline 1 & 100,0000 & 0,0000 & 5,3203 & 94,6797 \\
3 & 99,4954 & 0,5046 & 6,6126 & 93,3874 \\
5 & 97,8523 & 2,1477 & 11,8954 & 88,1046 \\
7 & 94,8108 & 5,1892 & 17,2723 & 82,7277 \\
9 & 91,2977 & 8,7023 & 21,8777 & 78,1223 \\
11 & 87,8496 & 12,1504 & 25,6192 & 74,3808 \\
13 & 84,6957 & 15,3043 & 28,6167 & 71,3833 \\
15 & 81,8997 & 18,1004 & 31,0235 & 68,9765 \\
17 & 79,4513 & 20,5488 & 32,9738 & 67,0262 \\
19 & 77,3133 & 22,6867 & 34,5735 & 65,4265 \\
21 & 75,4426 & 24,5574 & 35,9025 & 64,0975 \\
23 & 73,7985 & 26,2015 & 37,0204 & 62,9796 \\
25 & 72,3455 & 27,6545 & 37,9719 & 62,0281 \\
27 & 71,0541 & 28,9459 & 38,7905 & 61,2095 \\
29 & 69,8996 & 30,1004 & 39,5017 & 60,4983 \\
\hline
\end{tabular}


A produtividade consegue explicar $30 \%$ do erro de previsão da exportação na indústria de transformação, para uma previsão de 29 meses à frente. Da mesma forma, a exportação setorial consegue explicar (tendo em vista 29 meses à frente) 39,5\% dos erros de previsão da produtividade. Contrário ao modelo anterior, a exportação setorial (da indústria de transformação) tem maior capacidade de explicar os erros de previsão da variável referente a produtividade do trabalho do que a exportação no agregado (FOB).

\section{Conclusão}

A partir dos anos 90, o Brasil passou por um processo de abertura comercial, com o objetivo de expor a economia a uma maior competição, e tentando tornar a atividade econômica brasileira mais eficiente e produtiva dentro de um mundo que se tornava cada vez mais globalizado. Frente a tal processo e às consequências que ele possa suscitar, o estudo da atividade exportadora e seu relacionamento com a produtividade se torna cada vez mais essencial. Esta relação foi inicialmente explorada por obras clássicas, como em "A Riqueza das Nações", de Adam Smith, e em "Princípios da Economia Política”, de David Ricardo. O debate evoluiu para a análise da influência da atividade comercial internacional sobre o nível de crescimento de um país, trazendo à tona teorias como a ELG (Export-Led Growth), cujo principal argumento reside na capacidade das exportações em prover ganhos de escala na produção, levando a maior produtividade e competitividade.

Este trabalho teve como objetivo estudar a relação entre o nível de exportações e a produtividade na indústria de transformação brasileira durante o período de 2002-2019. Os dados adotados possuem periodicidade mensal, sendo que as exportações foram mensuradas de duas formas diferentes: FOB (a exportação como um todo, contando com diferentes indústrias) e setorial (contando apenas os setores que formam a indústria de transformação). A produtividade foi calculada com base na razão entre produção física e horas de trabalho na indústria de transformação. O câmbio real também foi incluído no modelo, devido à sua importância dentro do comércio internacional. Foram analisados dois modelos: um que relaciona produtividade com o nível de exportação no agregado (FOB), e outro que relaciona a produtividade, mas com o nível de exportação setorial (da indústria de transformação).

Os resultados apontaram que ambos os modelos apresentam uma relação de cointegração, com o câmbio sendo uma variável exógena no sistema. As estimativas dos modelos VECM então considerados apontaram resultados diferentes: quando se usa a exportação no agregado, observa-se que é a produtividade que leva a maiores níveis de exportações (como apontado pela teoria GLE Growth-Led Export). Porém, quando se observa a relação produtividade e exportação apenas na indústria de transformação, conclui-se que são as exportações que promovem a produtividade (mediante ganhos de escala, assim como apontado pela teoria ELG - Export-Led Growth). A análise das funções impulso-resposta revelou que, em ambos os modelos, choques nos níveis de exportações (seja no agregado ou setorial) produzem respostas positivas no nível de produtividade, porém tal efeito tende a ser decrescente com o passar dos meses.

As conclusões deste trabalho apontam que os policy makers devem atentar-se quanto à condução de políticas econômicas, afinal os resultados apontam que no agregado as exportações dependem do nível de produtividade. Logo, faz-se necessário alterar a produtividade (mediante 
alterações no nível tecnológico, por exemplo) para assim afetar o nível de exportações. Mas quando as medidas de política econômica se voltam apenas para a indústria de transformação, devem-se adotar medidas que buscam estimular o nível de exportação, de forma a proporcionar ganhos de produtividade para o setor. No entanto, cabe ressaltar que existem limitações na análise aqui desenvolvida como, por exemplo, no cálculo da produtividade, em que se usou apenas o insumo trabalho, constituindo uma medida parcial de produtividade apenas, sem considerar o insumo capital. Portanto, a consideração da produtividade total dos fatores de produção na avaliação empírica constitui tópico para pesquisa futura, assim como a incorporação das importações na dinâmica do sistema como elemento adicional para mensurar os impactos do comércio internacional, de forma geral, sobre o nível de produtividade.

\section{Referências bibliográficas}

ARAUJO, R.; SOARES, C. 'Export led growth' X 'growth led exports': what matters for the Brazilian growth experience after trade liberalization? MPRA Paper, n. 30562, posted 2. May 2011.

AVERBUG, André. Abertura e integração comercial brasileira na década de 90. In: GIAMBIAGI, Fabio; MOREIRA, Maurício Mesquita (Org.). A economia brasileira nos anos 90. Rio de Janeiro: Banco Nacional de Desenvolvimento Econômico e Social, 1999. p. 43-82.

AWOKUSE, T. O. Causality between exports, imports and economic growth: evidence for transition economies. Economies Letters, v. 94, p. 389-395, 2007.

AWOKUSE, T. Is the export-led growth hypothesis valid for Canada? The Canadian Journal of Economics, v. 36, n. 1, p. 126-136, 2003.

BECKERMAN, W. Demand, exports and growth. In: BECKERMAN \& Associates. Cambridge University Press, 1965. p. 44-72.

BHAGWATI, J. Foreign trade regimes and economic development: anatomy and consequences of exchange rate regimes. National Bureau of Economic Research, 1978. p. 182-204.

BONELLI, R.; PINHEIRO, A. C. (Org.). In: ENSAIOS IBRE DE ECONOMIA BRASILEIRA, 1. Rio de Janeiro: IBRE-FGV, 2013.

CAMPOS, F. M. Exportações, crescimento econômico e causalidade: evidências empíricas para o Brasil. In: ENCONTRO NACIONAL DA ASSOCIAÇÃO BRASILEIRA DE ESTUDOS REGIONAIS E URBANOS, 7, 2009. São Paulo. VII ENABER. Anais...

CLERIDES S.; LACH, S.; TYBOUT, J. Is learning by exporting important? Micro-dynamic evidence from Colombia, Mexico, and Morocco. The Quarterly Journal of Economics, v. 113, n. 3, p. 903947, 1998.

DAVIDSON, P. A lei de Thirlwall. Revista de Economia Política, v. 10, n. 4, 1990.

DICKEY, D.; FULLER, W. The likelihood ratio statistics for autoregressive time series with a unit root. Econometrica, v. 49, n. 4, p. 1057-1072, 1981.

ENDERS, W. Applied econometrics time series. 4. ed. John Wiley e Sons Inc., 2015. 
FASANO FILHO, U. A expansão das exportações e o crescimento econômico: o caso do Brasil, 1969-84. Revista Brasileira de Economia, v. 42, n. 1, p. 73-81, 1988.

FEDER, G. On export and economic growth. Journal of Development Economics, v. 12, p. 59-73, 1982.

FERREIRA, P. C.; ELLERY, R.; GOMES, V. Produtividade agregada brasileira (1970-2000): declínio robusto e fraca recuperação. Estudos Econômicos, v. 38, n. 1, 2008.

GHATAK, S.; MILNER, C.; UTKULU, U. Exports, export composition and growth: cointegration and causality evidence for Malaysia. Applied Economics, v. 29, n. 2, p. 213-223, 1997.

HAY, D. The post 1990 Brazilian trade liberalization and the performance of large manufacturing firms: productivity, market share and profits. IPEA,1997. (Texto para Discussão).

HERZER. D.; FELICITAS, D.; SILIVERSTOVIS, B. Export-led growth in Chile: Assessing the role of export composition in productivity growth. The Developing Economis, v. 44, n. 3, p. 306-328, 2006.

HIDALGO, A.; MATA, D. Produtividade e desempenho exportador das firmas na indústria de transformação brasileira. Estudos Econômicos, v. 39, n. 4, p. 709-735, 2009.

IBGE. Instituto Brasileiro de Geografia e Estatística. Disponível em: http://www.ibge.gov.br/home/.

JOHANSEN, S. Statistical analysis of cointegration vectors. Journal of Economic Dynamics and Control, v. 12, n. 1-3, p. 231-254, 1988.

KALDOR, N. The case for regional policies. Scottish Journal of Political Economy, v. 17, p. 337$348,1970$.

KAUSHIK, K.; ARBENSER, A. Export growth, export instability, investment and economic growth in India: a time series analysis. The Journal of Developing Areas, v. 41, n. 2, 2008.

KEONG, C.; YUSOP, Z.; LIEW, V. Export-led growth hypothesis in Malaysia: an investigation using bounds test. Sunway Academic Journal, v. 2, p. 13-22, 2005.

KNUST, M.; MARIN, D. On exports and productivity: a causal analysis. The Review of Economic and Statistics, v. 71, n. 4, p. 699-703, 1989.

KRUGMAN, P. Import protection as export protection. In: KIERKOWSKY, H. (Ed.). Monopolistic competition and international trade. Oxford: Oxford University Press, 1984. p. 180-193.

KWIATKOWISK, D.; PHILLIPS, P.; SCHMIDT, P.; SHIN, Y. Testing the null hypothesis of stationarity against the alternative of a unit root: how sure are we that economic time series have a unit root? Journal of Econometrics, v. 54, n. 1-3, p. 159-178, 1992.

LAMFALUSSY, A. The meaning and implications of export-led growth. The United Kingdom and the Six, Palgrave Macmillan, London, 1963.

LANCASTER, K. Intra-industry trade under perfect monopolistic competition. Journal of International Economics, v. 10, n. 2, p. 151-175, 1980. 
LIU, L. Entry-exit, learning and productivity change: Evidence from Chile. Journal of Development Economics, v. 42, n. 2, 1993.

MELITZ, M.; OTTAVIANO, G. Market size, trade and productivity. Review of Economic Studies, v. 75, p. 295-316, 2008.

MELO, J.; ROBINSON, S. Productivity and externalities: models of export-led growth. The Journal of International Trade \& Economic Development, v. 1, n. 1, p. 41-68, 1992.

NORTH, D. Location theory and regional economic growth. Journal of Political Economy, v. 63, n. 3, 1955.

RICARDO, D. Princípios de economia política e tributação. Tradução de Paulo Henrique Ribeiro Sandroni. São Paulo: Nova Cultural Ltda., 1996. (Coleção os Economistas).

ROMER, P. Endogenous technological change. Journal of Political Economy, v. 98, n. 5, p. 71-102, 1990.

ROSSI JR., J. L.; FERREIRA, P. C. Evolução da produtividade industrial brasileira e abertura comercial. IPEA, 1999. (Texto para Discussão, n. 651).

SHAN, J.; TIAN, G. G. Causality between exports and economic growth: the empirical evidence from Shanghai. Australian Economic Papers, v. 37, n. 2, p. 195-202, 1998.

SHARMA, C.; MISHRA, R. International trade and performance of firms: unraveling export, import and productivity puzzle. The Quarterly Review of Economics and Finance, v. 57, p. 61-74, 2015.

SILAGHI, P. Exports-economic growth causality: Evidence from CEE countries. Romanian Journal of Economic Forecasting, v. 2, p. 105-117, 2009.

SILVA, D. O impacto da abertura comercial sobre a produtividade da indústria brasileira. Dissertação (Mestrado em Finanças e Economia Empresarial)-Escola de Pós-Graduação em Economia, Fundação Getúlio Vargas (FGV), São Paulo, 2004.

SILVA, I.; BEZERRA, J.; LIMA. R. As exportações promovem a produtividade? Evidência empírica para indústria de transformação do Brasil utilizando vetores autoregressivos com correção de erro (VEC). EconomiA, v. 13, n. 1, p. 67-91, 2012.

SMITH, A. A riqueza das nações: investigação sobre sua natureza e suas causas. Tradução de Luiz João Baraúna. São Paulo: Nova Cultural Ltda., 1996. (Coleção Os Economistas).

SOLOW, R. Technical change and the aggregate production function. Review of Economics and Statistics, v. 39, p. 312-320, 1957.

THIRWALL, A. P. The balance of payments constraint as an explanation of international growth rate differences. Banca Nationale del Lavoro Quarterly Review, v. 32, p. 45-53, 1979.

THORNTON, J. Cointegration, causality and export-led growth in Mexico 1895-1992. Economics Letters, v. 50, n. 3, p. 413-419, 1996.

YOUNG, A. A. Increasing returns and economic Progress. The Economical Journal, v. 38, n. 152, p. 527-542, 1928. 